\title{
Discovering the True Chrysoperla carnea (Insecta: Neuroptera: Chrysopidae) Using Song Analysis, Morphology, and Ecology
}

\author{
CHARLES S. HENRY, ${ }^{1}$ STEPHEN J. BROOKS, ${ }^{2}$ PETER DUELLI, ${ }^{3}$ AND JAMES B. JOHNSON ${ }^{4}$ \\ Department of Ecology and Evolutionary Biology, University of Connecticut, Storrs, CT 06269-3043
}

Ann. Entomol. Soc. Am. 95(2): 172-191 (2002)

\begin{abstract}
What was once considered a single Holarctic species of green lacewing, Chrysoperla carnea (Stephens), has recently been shown to be a complex of many cryptic, sibling species, the carnea species group, whose members are reproductively isolated by their substrate-borne vibrational songs. Because species in the complex are diagnosed by their song phenotypes and not by morphology, the current systematic status of the type species has become a problem. Here, we attempt to determine which song species corresponds to Stephens' 1835 concept of C. carnea, originally based on a small series of specimens collected in or near London and currently housed in The Natural History Museum. With six European members of the complex from which to choose, we narrow the field to just three that have been collected in England: C. lucasina (Lacroix), Cc2 'slow-motorboat', and Cc4 'motorboat'. Ecophysiology eliminates C. lucasina, because that species remains green during adult winter diapause, while $C c 2$ and $C c 4$ share with Stephens' type a change to brownish or reddish color in winter. We then describe the songs, ecology, adult morphology, and larval morphology of Cc2 and Cc4, making statistical comparisons between the two species. Results strongly reinforce the conclusion that $C c 2$ and $C c 4$ deserve separate species status. In particular, adult morphology displays several subtle but useful differences between the species, including the shape of the basal dilation of the metatarsal claw and the genital 'lip' and 'chin' of the male abdomen, color and coarseness of the sternal setae at the tip of the abdomen and on the genital lip, and pigment distribution on the stipes of the maxilla. Furthermore, behavioral choice experiments involving playback of conspecific versus heterospecific songs to individuals of $C c 2$ and $C c 4$ demonstrate strong reproductive isolation between the two species. Comparison of the adult morphology of song-determined specimens to that of preserved specimens in the original type series and in other collections in The Natural History Museum, London, indicate that the 'true' Chrysoperla carnea (Stephens) is Cc4. Cc2 cannot be confidently associated with any previously described species and is therefore assigned a new name, Chrysoperla pallida sp. nov., and formally described.
\end{abstract}

KEY WORDS systematics, courtship song, tremulation, sibling species, cryptic species, Europe

SYSTEMATICS IS OPEN to the use of nearly any type of character, limited only by the resourcefulness of the practitioner. Although the gross physical (morphological) traits of plants and animals are the ones most commonly used by systematists, the literature abounds with studies that draw heavily from life-history characteristics, ontogeny, ecophysiology, niche dimensions, host or habitat associations, ultrastructure, molecular traits, and behavior. In fact, some clades consist of species that are diagnosed most accurately by characters that require special skills or

\footnotetext{
${ }^{1}$ E-mail: chenry@uconnvm.uconn.edu.

2 Department of Entomology, The Natural History Museum, Cromwell Road, London SW7 5BD, England, UK

${ }^{3}$ Swiss Federal Institute for Forest, Snow and Landscape Research, CH-8903 Birmensdorf, Switzerland.

${ }^{4}$ Division of Entomology, Department of Plant, Soil, and Entomological Sciences, College of Agriculture, Moscow, ID 83844.
}

sophisticated techniques to uncover or assess (for recent examples from diverse groups, see Paterson 1991, Sweeney and Funk 1991, Vrijenhoek et al. 1994, Bernardi and Goswami 1997, Green et al. 1997, Jones 1997, Wilcox et al. 1997, Jackson and Resh 1998, Baric and Sturmbauer 1999). In those cases, one might argue (e.g., as have Tauber et al. 2000) that cryptic species are of little utility, because we cannot easily tell them apart by their physical appearance. However, delineating the fabric of biological diversity, whether such diversity is hidden or obvious, is of great importance to every field of organismic biology, providing key insights into both fundamental and applied areas of research.

The biological or reproductive species concept (Mayr 1963, Templeton 1989) assumes no a priori correlation between speciation and morphology, placing emphasis instead upon reproductive isolation and 
mate recognition. Nevertheless, most clades of animals or plants manifest at least some consistent morphological indication of the differences among their component species; if they do not, their constituents are referred to as sibling or cryptic species (Mayr 1963, Knowlton 1986). Green lacewings of the genus Chrysoperla Steinmann include at least one large clade of strikingly cryptic species, informally known as the 'carnea group' (Duelli 1996). Originally, this complex was considered to be a single Holarctic species, Chrysoperla carnea (Stephens), based upon many adult specimens of remarkably similar morphology found all across North America, Europe, northern Africa, and Asia (Tjeder 1960). Several attempts were made to carve additional species out of ' $C$. carnea' using subtle color differences among adults and larvae (Hölzel 1972; Leraut 1991, 1992), but the results were not very satisfactory (Brooks 1994). Much more promising as diagnostic tools are recently discovered behavioral barriers to gene flow among lacewing populations, which have led to the realization that Chrysoperla carnea is but one member of a diverse carnea group.

Green lacewings of the carnea group produce substrate-borne songs by abdominal vibration when sexually receptive. The abdomen does not strike the substrate, but instead the insect 'shakes' the leaf or conifer needle upon which it is standing - a process known as tremulation (Henry 1980a, Morris 1980, Michelsen et al. 1982). These vibrational songs cannot attract potential mates over great distances but instead serve a discriminatory function at relatively close range. Both sexes sing, thus allowing individuals to match their mating signals to one another during a prolonged heterosexual duet as a prerequisite to copulation. Because song phenotype is under strict genetic control, individuals that possess different songs will fail to match up, resulting in reproductive isolation of populations characterized by different songs (Henry 1985, Wells and Henry 1992a). At least 15 highly distinct, reproductively isolated song populations have been identified within the Holarctic carnea group to date, and it is clear that many more remain to be described (Wells and Henry 1998, Henry et al. 1999a). From a systematic perspective, these represent cryptic but valid species within the complex, identifiable principally or solely by their substrate-borne vibrational songs (Henry et al. 1993). Unfortunately, it is usually difficult or impossible to assign specimens to such acoustically diagnosed species, because the taxonomist needs access to living specimens and special training at recognizing song phenotypes (Henry et al. 2001).

Chrysoperla carnea was first described in England (as Chrysopa carnea) by J. F. Stephens (1835). The species was based on a short type series collected in London and Scotland and is presently housed in The Natural History Museum, London, UK (BMNH). Currently, it is impossible to know how many specimens comprised the original type series. According to Kimmins (1964), Stephens' specimens "were arranged above a specific label, no names being placed on the specimens themselves. At some time the specimens were moved to what appeared to be their correct species, but no note was attached to them to indicate their original identification, apart from attaching the specific name to one of the original series. In consequence it is now difficult to be certain to which series some of the specimens belonged." Among the specimens moved to the carnea series was the type series of C. affinis Stephens, which included specimens collected in London, Dover and Devonshire, as well as specimens identified by Stephens as 'C. alba (L.)', collected in London and the New Forest. ['C. alba (L.)' is now a synonym of Chrysotropia ciliata (Wesmael). It was recognized that the alba specimens in Stephens' collection were actually C. carnea s. lato and moved them into the carnea series where, to the unwary, they may seem to be part of the original C. carnea type series. The alba specimens therefore have no validity as type specimens.] Subsequently, Leraut (1991) designated the specimen bearing the label 'car$n e a$ ' as the lectotype of $C$. carnea and the specimen bearing the label 'affinis' as the lectotype of C. affinis.

For the past $10 \mathrm{yr}$, we have been involved in a comprehensive investigation of the song species of England and neighboring Eurasia to determine the extent of hidden taxonomic diversity in the carnea group there. Our initial steps toward that goal were to describe two European song species that loosely matched morphological 'entities' that had been described earlier: Chrysoperla lucasina (Lacroix) and C. mediterranea (Hölzel) (Henry et al. 1996, 1999b). However, four other song species were discovered in Europe and the Arabian Peninsula, which were not clearly associated with existing morphotypes in the literature (Wells and Henry 1998, Henry et al. 2001). Those have been informally called Cc2 'slow-motorboat', Cc3 'Maltese', Cc4 'motorboat', and Cc5 'generator', using a naming convention first proposed by Duelli (1996) with descriptors reflecting the acoustic properties of the song or the site of first collection. Despite the physical similarity of these four song species, some workers claim that two of them, $C c 2$ and $C c 4$, can be identified in mainland Europe using a suite of morphological characters that includes the color of the ventral setae on the distal portion of the abdomen (blond versus black), the dark markings on the maxillary stipes (slight versus extensive), and the shape of the basal dilation of the hind pretarsal claws (broad versus narrow) (Leraut 1991 1992, Thierry et al. 1992 1998). More recently, the shape of the genital lip at the apex of sternites $8+9$ of the male abdomen (short and narrow versus long and broad) has been proposed as a character to separate $C c 2$ from $C c 4$ (e.g., Fig. 5, and see also Table 1 in Henry et al. 2001).

In this article, we apply a broad range of information from bioacoustics, behavior, morphology, biogeography, ecology, ecophysiology, and molecular phylogeny toward the solution of an important problem in lacewing systematics. If Chrysoperla carnea is a complex of many cryptic species, then which one of the four remaining unassigned song species from Europe is the 'true carnea' of Stephens, now fixed by the lectotype specimen? We first describe biogeographic and ecophysiological evidence that implicates $C c 2$ and 
Table 1. Collecting sites for living $C c 2$ 'slow-motorboat' and $C c 4$ 'motorboat', 1981-2001

\begin{tabular}{|c|c|c|c|c|c|}
\hline Local Site (with nearest city or region) & Country & Altitude, $\mathrm{m}$ & Latitude & Year & Sympatric \\
\hline Kifissia (Athens) & Greece & 300 & $38^{\circ} 12^{\prime}$ & vi-2001 & $C c 2,{ }^{a} 3$, luca, med \\
\hline Cabrera (Madrid) & C Spain & 1,050 & $40^{\circ} 58^{\prime}$ & 20 -vii-95 & $\mathrm{Cc} 2{ }^{a}{ }^{a}$ luca, med \\
\hline Carcès & S France & 180 & $43^{\circ} 20^{\prime}$ & 1994,1997 & $C c 2,{ }^{b} 3$, luca, med \\
\hline Terrasson and Tulle (Brive-la-Gaillarde) & W France & 380 & $45^{\circ} 10^{\prime}$ & 25 -vii-95 & $C c 2,{ }^{a}$ luca \\
\hline Modane (S slope of Alps) & E France & 1,080 & $45^{\circ} 12^{\prime}$ & vii-1993 & $C c 4$ \\
\hline St. Didier (Aøsta, S slope of Alps) & NW Italy & 1,000 & $45^{\circ} 45^{\prime}$ & vii-1993 & Cc4 \\
\hline Cavaglio \& Traffiume (S slope Alps) & N Italy & 500 & $46^{\circ} 30^{\prime}$ & iv/vi-1994 & $C c 2,{ }^{b} 3,4^{b}$ \\
\hline Campocologno (S slope of Alps) & S Switzerland & 530 & $46^{\circ} 30^{\prime}$ & vii-1994 & $C c 4^{a, b}$ \\
\hline Angeli Custodi (S slope of Alps) & S Switzerland & 1,130 & $46^{\circ} 30^{\prime}$ & vi-1994 & Cc4 \\
\hline $\begin{array}{l}\text { Ticino: Monte Caslano, Biasca, Agarone, } \\
\text { Piodina, Brissago (S slope of Alps) }\end{array}$ & S Switzerland & $275-820$ & $46^{\circ} 30^{\prime}$ & 1981-’94 & $C c 2,{ }^{b} 3,4^{b}$ luca \\
\hline Geneva ( $\mathrm{N}$ slope of Alps) & SW Switzerland & 450 & $46^{\circ} 14^{\prime}$ & 1999 & $C c 2$ \\
\hline Pfynwald: Sierre (N slope of Alps) & SW Switzerland & 600 & $46^{\circ} 30^{\prime}$ & 1984-1997 & Cc2 $2{ }^{a}$ luca, med \\
\hline Bolligen (Bern; N slope of Alps) & N Switzerland & 530 & $47^{\circ} 00^{\prime}$ & 1993-1994 & $C c 4^{b}$ \\
\hline Betlis ( $\mathrm{N}$ slope of Alps) & N Switzerland & 420 & $47^{\circ} 06^{\prime}$ & 22-ix-1994 & Cc4 \\
\hline Zürich ( $\mathrm{N}$ slope of Alps) & N Switzerland & 520 & $47^{\circ} 22^{\prime}$ & 1983-1996 & $C c 2,{ }^{b} 4,^{b}$ luca \\
\hline Vouvray (Amboise) & C France & 50 & $47^{\circ} 25^{\prime}$ & 1999,2000 & $C c 2,{ }^{b} \mathrm{Cc} 4$ \\
\hline Pont-à-Mousson (N slope of Alps) & NE France & 250 & $48^{\circ} 55^{\prime}$ & 27 -vii-95 & $C c 2$ \\
\hline Brückl (Hölzel) & Austria & 1,000 & $47^{\circ} 25^{\prime}$ & $10-\mathrm{x}-1994$ & Cc4, med \\
\hline Berchtesgaden (N slope of Alps) & S Germany & 600 & $47^{\circ} 35^{\prime}$ & 8-ix-1994 & $C c 4^{b}$ luca \\
\hline $10 \mathrm{~km} \mathrm{~N}$ of Lake Balaton (on Quercus) & Hungary & 300 & $47^{\circ} 05^{\prime}$ & 12 -viii-2000 & Cc2 2 \\
\hline Banovce (Czech border; alfalfa) & Slovak Republic & 300 & $48^{\circ} 48^{\prime}$ & 6-viii-1994 & Cc4, luca \\
\hline Nova Lehota (near Banovce; shrubs) & Slovak Republic & 600 & $48^{\circ} 48^{\prime}$ & 4 -viii-1994 & Cc4, med \\
\hline Harmanci (mountain pass, on Acer) & Slovak Republic & 800 & $48^{\circ} 48^{\prime}$ & 5-viii-1994 & Cc4 \\
\hline Zbraslav (S Praha; at lights) & Czech Republic & 150 & $50^{\circ} 05^{\prime}$ & 6-viii-1994 & $\mathrm{Cc4}$ \\
\hline Praha (N Praha; pine and oak) & Czech Republic & 150 & $50^{\circ} 05^{\prime}$ & 3-viii-1994 & $C c 4$ \\
\hline Rachiv (Transkarpatia; on grass) & Ukraine & 400 & $48^{\circ} 00^{\prime}$ & 1995,1998 & $C c 4^{b}$ \\
\hline Belgorod, Belgorod & Russia & 150 & $50^{\circ} 42^{\prime}$ & xii-1997 & $C c 4^{b}$ \\
\hline Gembloux & Belgium & Sea level & $51^{\circ} 20^{\prime}$ & iii-1995 & $C c 4^{a, b}$ \\
\hline New Forest, Hampshire (heath) & S. England & $<100$ & $51^{\circ} 01^{\prime}$ & 11-ix-1994 & Cc4, luca \\
\hline London (NHM and Palace gardens) & S. England & $<100$ & $51^{\circ} 30^{\prime}$ & 1994,2000 & $C c 2, C c 4$ \\
\hline Silwood Park, Ascot (forest edge) & S. England & $<100$ & $51^{\circ} 30^{\prime}$ & xi/xii-2000 & Cc2, Cc4, luca \\
\hline Hemyock, Devon (deciduous plants) & SW England & $<100$ & $51^{\circ} 30^{\prime}$ & 2-ix-1994 & $\mathrm{Cc4}$ \\
\hline Southend-on-sea, Essex & SE England & Sea level & $51^{\circ} 33^{\prime}$ & 28-x-1994 & Cc4 \\
\hline Minsmere Reserve (Eastbridge) & SE England & Sea level & $51^{\circ} 33^{\prime}$ & 29-vii-1995 & Cc4, luca \\
\hline St Albans, England (garden) & S England & $<100$ & $51^{\circ} 44^{\prime}$ & ix-1994 & Cc4 \\
\hline York University (heath land) & C England & $<100$ & $53^{\circ} 58^{\prime}$ & 1-ix-1994 & Cc4, luca \\
\hline East Lothian (Edinburgh; garden) & S Scotland & 70 & $55^{\circ} 56^{\prime}$ & $\mathrm{x}-1999$ & $\mathrm{Cc} 4$ \\
\hline Shetland Islands (main island) & N Scotland & $<100$ & $60^{\circ} 35^{\prime}$ & $24-x-1994$ & $C c 4$ \\
\hline Eidvig (Lita Greve site) & C Norway & $<100$ & $60^{\circ} 24^{\prime}$ & 1994 & Cc4 \\
\hline Jokioinen \& Tammela (agricultural) & S Finland & $<100$ & $61^{\circ}$ & 1994 & $C c 4^{b}$ \\
\hline
\end{tabular}

Abbreviations: luca for C. lucasina and med for C. mediterranea. ${ }^{a}$ Song confirmed and measured but not included in this study.

${ }^{b}$ Larvae also obtained.

Cc4 as the most probable candidates for the type species and exclude the other two $(C c 3$ and $C c 5)$ from consideration. Accordingly, we present song descriptions of $C c 2$ and $C c 4$, testing for significant differences between each of their shared song features and then comparing their song phenotypes to those of all other known song species of Europe. We show behavioral and ecological data that support their complete reproductive isolation from each other, thereby confirming their distinctiveness and supporting the validity of their status as full species. Results of a comprehensive morphological analysis of both adults and larvae of $C c 2$ and $C c 4$ are then presented. Because these two are the very taxa thought by some systematists to be morphologically separable in mainland Europe (see above), we pay particular attention to the consistency (and diagnostic power) of setal color, maxillary markings, claw basal dilation, abdominal shape, and larval head markings across the full geographical range of each species. Those results are compared with observations and measurements taken on existing carnea-group specimens in the Stephens' Collection and in the British Collection at the BMNH to link by adult morphology one or the other of the two song species to the British lacewing fauna in general and to Stephens' series in particular. Using all available evidence, we designate one of the two song species as Chrysoperla carnea (Stephens) and assign the name Chrysoperla pallida sp. nov. to the other song species.

\section{Materials and Methods}

Collecting, Rearing, and Identification. Living adults of the carnea species-group of Chrysoperla were collected by the authors or their associates from 1977 to 2001 across most of North America and Europe, portions of Asia and northern Africa, the British Isles, Fennoscandia, and several islands and archipelagoes in the Mediterranean Sea and eastern North Atlantic. All insects were shipped or hand-carried to Storrs, CT, USA. They were segregated by song, locality and sex, placed in groups of 10-14 individuals under long-day 
photoperiod of 17:7 (L:D) h in low-profile clear plastic champagne cups inverted over 10 -cm petri dish lids, and supplied with water and a Wheast-based diet (Hagen and Tassan 1970). Field-collected females laying fertile eggs were not sexually receptive (Henry and Busher 1988); in those cases, progeny were reared to adulthood using established methods (Henry 1991, 1993) and then tested for courtship songs. For all individuals, the ground color of the body was recorded at the time of collection, principally to determine the presence or absence of color changes associated with winter diapause (such colors fade in preserved specimens).

Individuals were identified to species using playback of a series of previously recorded song types to each insect from a computer through an amplifier and loudspeaker (see below). Morphology was used to confirm species determinations in those few species of the carnea group possessing consistently distinctive physical features, e.g., Chrysoperla downesi (Smith), C. lucasina, and C. mediterranea (Brooks 1994; Henry et al. 1996, 1999b). Several specimens of verified song phenotype from each population were also deep frozen at minus $70-100^{\circ} \mathrm{C}$ for molecular systematic studies (Henry et al. 1999a), whereas others were deposited as vouchers in (1) the collection of C. S. Henry, Storrs; (2) the Connecticut State Museum of Natural History, Storrs (CSMNH); (3) The Natural History Museum, London (BMNH); (4) Yale Peabody Museum, New Haven (YPM); (5) the collection of Peter Duelli, Birmensdorf, Switzerland (SFIFSL); and (6) the W. F. Barr Museum, Moscow, ID (WFBM). As the study progressed, focus shifted to $\mathrm{Cc} 2$ 'slow-motorboat' and Cc4 'motorboat'. Complete collecting records for all specimens of those two song species are given in Table 1.

Ecology and Ecophysiology. Ecological and ecophysiological observations were noted at the time of collection of individual specimens and recorded from laboratory-reared individuals over a period of about 20 yr. Information about species composition of lacewings in agricultural lands was obtained by collecting along $5-\mathrm{km}$ transects established through crop fields in the Limpach valley near Berne, Switzerland, during the summers of 1987 and 1997 (P.D., unpublished data). Detailed year-long faunal surveys of five forest edge sites were also conducted in the same Limpach area during 1994 and 1995 as part of a large project on arthropod biodiversity. An earlier 1983 study (Duelli 1988) assessed weekly movements of lacewings into and out of a 1-ha maize field near Basel, Switzerland, using four sticky grid traps ( $7 \mathrm{~m}$ high by $1 \mathrm{~m}$ wide) placed on each side of the field.

Song Analysis. In the laboratory, lacewings will tremulate inside a small cardboard coffee cup covered with plastic wrap (the arena). Their vibrational signals were detected by a piezoelectric transducer touching the plastic wrap and recorded on cassette tape (see Henry 1979, 1980a for details). The same arena was used for playback experiments. Recorded songs from tape or digitized on computer disk were played through a speaker placed just above the arena, causing the plastic wrap to reproduce the low frequencies faithfully in the speaker's near-field.

At least five complete courtship songs (=shortest repeated units or SRUs) of 10-71 individuals of each lacewing species were recorded at $25 \pm 1^{\circ} \mathrm{C}$ on cassette tape with Dolby disabled. Recordings were then digitized, using a Cambridge Electronic Design (CED, Cambridge, England) 1401 plus Intelligent Laboratory Interface or a Data Translation (Marlboro, MA) DT2821 with 32-bit digital signal processing (DSP) board. Songs were analyzed using CED's Spike2, version 3.13-3.15 (Smith 1995) and Engineering Design's (Belmont, MA) Signal/RTS Sound Analysis System, version 3.0 (Beeman 1996). Males and females were induced to sing by playing recorded songs of conspecifics. Song features in the frequency domain were measured using both FFT and zero-crossing methods, the latter permitting accurate measurement of frequency change over very short time periods in puretone signals.

The substrate-borne courtship songs of Chrysoperla green lacewings consist of volleys of low-frequency (30-120 Hz) abdominal vibration repeated with a regular period. Each volley can also exhibit carrier frequency modulation. Some taxa, such as Nearctic $C$. plorabunda (Fitch) and C. adamsi Henry, Wells \& Pupedis have relatively simple songs, composed of single-volley (monosyllabic) SRUs repeated many times (Henry et al. 1993). Other species, including Cc2 and $\mathrm{Cc4}$ (Fig. 1), produce more complex songs that consist of much longer, multisyllabic SRUs, repeated only in response to other such songs (Henry 1980b). In those forms, volley carrier frequency may change over the course of the SRU as well as within a volley. To characterize and analyze the full range of song variation found across the study taxa, 17 song features were measured for each song species. Those included the eleven features shown for $C c 2$ and $C c 4$ in Tables 2 and 3, plus six more associated with frequency changes within single volleys selected from different positions in the SRU (see below).

Detailed song analyses were performed on 43 individuals of $C c 2$ and 71 individuals of $C c 4$. Although many populations throughout Europe were sampled (Table 1), we grouped those into five regional areas (Fig. 2): south-central France (6 Cc2, 0 Cc4 individuals), the Alps $(30,27)$, the United Kingdom $(7,16)$, Fennoscandia $(0,15)$ and eastern Europe $(0,13)$. As mentioned above, these two species have complex, long songs in which the SRU contains many similar volleys. Volleys are short but show significant frequency modulation both within each volley and between volleys over the course of the entire SRU (see Figs. 1 and 3). Consequently, several song characteristics were measured multiple times and tabulated as distinct features (Tables 2 and 3). For example, carrier frequency was measured at the start, middle and end of volleys found at the beginning, middle, and end of each SRU (within-volley start and end values are not shown in the tables), to encompass all consistent pitch variation. Similarly, volley duration and period were measured for each of the three different sections of 

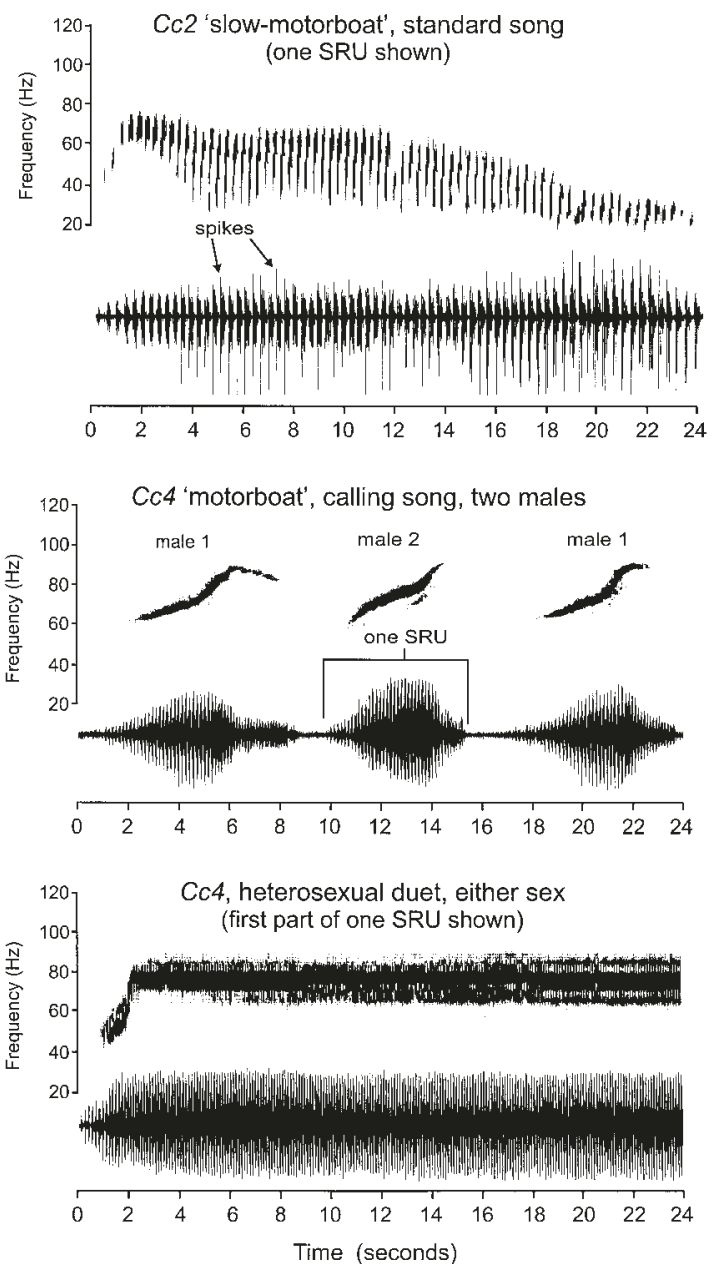

Fig. 1. Oscillographs (lower of each pair of traces) and sonographs (upper traces) of typical songs of the European song species $C c 2$ 'slow-motorboat' and $C c 4$ 'motorboat' of the carnea group of Chrysoperla, drawn to a common time scale of $24 \mathrm{~s}$. In both song species, sexual partners duet by politely exchanging long, multi-volley SRUs (shortest repeated units). Cc4 has two different types of songs, differing principally in SRU length; both types are illustrated in the figure. Cc4 is the 'true' Chrysoperla carnea described originally by Stephens (1835), while Cc2 is Chrysoperla pallida sp. nov.

each SRU. For each feature thus delineated, measurements on six volleys per section were averaged together. Then, for each of 5-10 SRUs per individual, we calculated the mean value of each song feature and took the mean (i.e., $n=$ number of repeated song measurements per individual) of those means as the representative value of the feature for each individual. A paired $t$-test (Snedecor and Cochran 1980) was performed on those individual averages, comparing $C c 2$ and $C c 4$ with respect to statistically significant differences in the population means of each feature. Coefficients of variation were also calculated, first for each individual (within-individual variation) and then for each species (between-individual variation). $\mathrm{Fi}$ - 


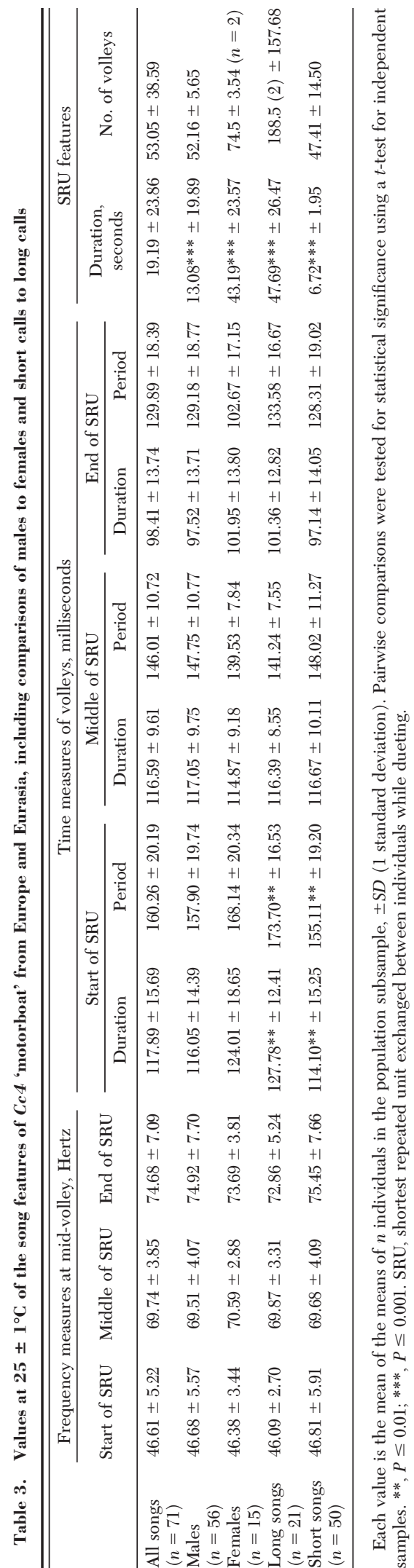

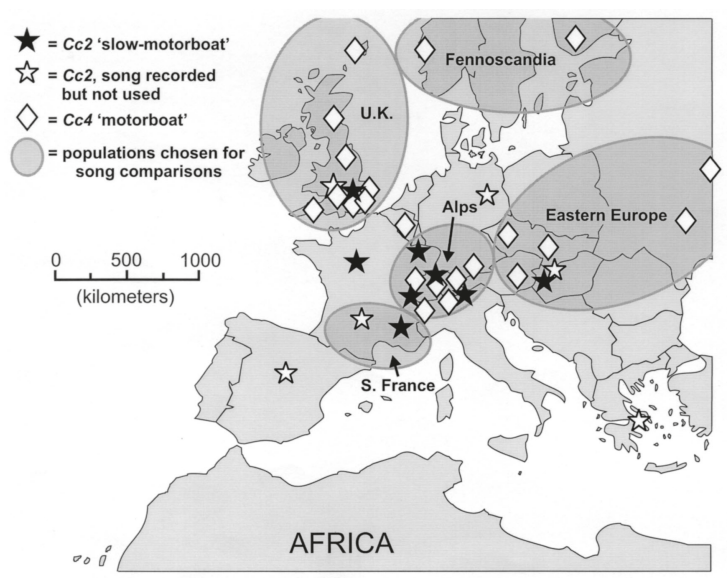

Fig. 2. Collecting sites of Cc2 (C. pallida) and Cc4 (C. carnea) in Europe, with ellipses drawn around the discrete geographical areas used for song comparisons. For sites labeled "song recorded but not used," individuals were nevertheless assigned to song species by assessing song phenotype.

Cc2 'slow-motorboat' (4 volleys)
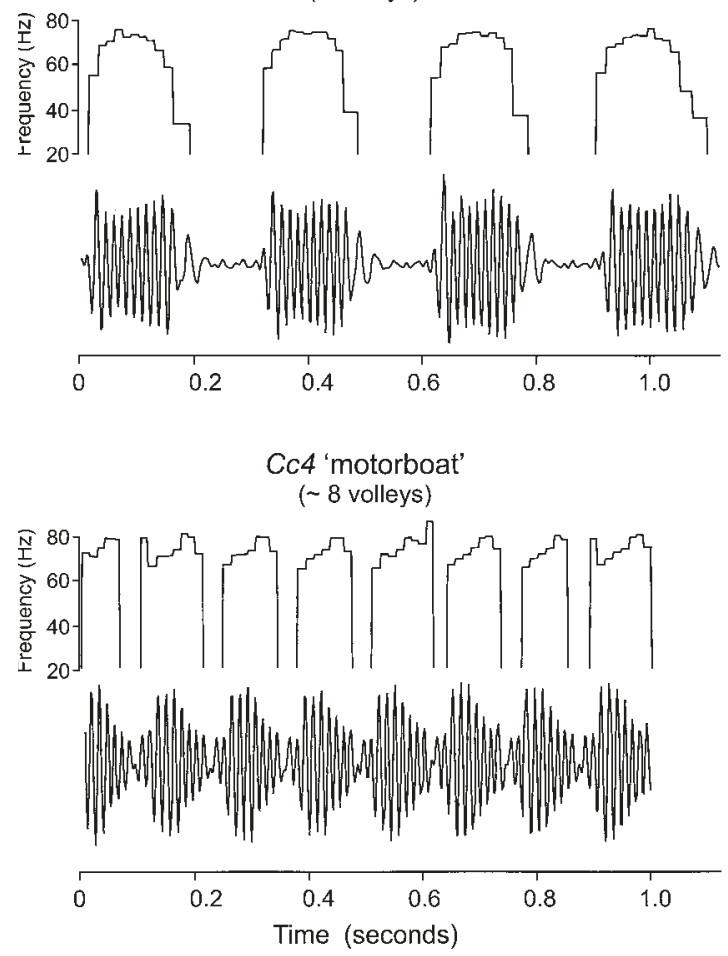

Fig. 3. One-second segments extracted from the songs of Cc2 (C. pallida) and Cc4 (C. carnea), showing amplitude and frequency characteristics of individual volleys of abdominal vibration. The plots of instantaneous frequency (upper of each pair of traces) were produced using the zero-crossing method (see text). 
Table 4. Results of a discriminant function analysis of the six 'least correlated' song measurements of nine song species of the carnea group of green lacewings, showing squared Mahalanobis distances (above the diagonal) and $F$-values (below the diagonal)

\begin{tabular}{lcccccccrr}
\hline \hline & plorabunda & $\begin{array}{c}\text { adamsi } \\
\text { (N. Amer.) }\end{array}$ & $\begin{array}{c}\text { 'adamsi-K' } \\
\text { (Asia) }\end{array}$ & johnsoni & mediterranea & lucasina & $\begin{array}{c}\text { downesi } \\
\text { (mohave) }\end{array}$ & $\begin{array}{c}\text { Cc2 } \\
\text { 'slow-moto' }\end{array}$ & $\begin{array}{c}\text { Cc4 } \\
\text { 'motorboat' }\end{array}$ \\
\hline plorabunda & - & 38.60 & 48.78 & 49.01 & 72.65 & 170.56 & 88.58 & 38.37 & 55.84 \\
adamsi & 209.66 & - & 7.02 & 30.90 & 135.98 & 203.57 & 144.95 & 74.36 & 95.45 \\
'adamsi-K' & 198.49 & 27.34 & - & 42.56 & 145.62 & 227.88 & 161.70 & 113.03 & 131.14 \\
johnsoni & 329.24 & 193.07 & 191.99 & - & 115.18 & 145.88 & 118.20 & 71.35 & 88.58 \\
mediterranea & 373.40 & 661.02 & 544.63 & 675.58 & - & 41.37 & $5.43^{a}$ & 69.11 & 64.50 \\
lucasina & 1271.56 & 1401.17 & 1101.14 & 1325.45 & 265.64 & - & 31.00 & 112.28 & 93.11 \\
downesi & 200.18 & 319.49 & 313.77 & 282.47 & $11.70^{a}$ & 76.78 & - & 64.83 & 71.66 \\
Cc2 & 163.91 & 303.21 & 368.26 & 339.72 & 270.25 & 574.94 & 128.71 & - & 16.41 \\
Cc4 & 308.41 & 496.63 & 516.59 & 564.31 & 318.25 & 654.62 & 159.01 & 67.74 & - \\
\hline
\end{tabular}

Song features in the analysis included (1) volley duration at mid-SRU, (2) volley period at mid-SRU, (3) SRU duration, (4) midvolley frequency at SRU start, (5) end-volley frequency at SRU start, and (6) initial volley frequency at mid-SRU. All $F$-values were statistically significant at $P<0.00000$. Wilks' Lambda $=0.00016$, approximate $F=287.70 ; \mathrm{df}=48,2,793$.

${ }^{a}$ Shortest distance found, between C. mediterranea and C. downesi (mohave).

nally, within each species, an analysis of variance (ANOVA) was performed on individual averages using geographic region as the independent variable, and Scheffé's contrast tests (Scheffé 1953) were applied to pinpoint significant differences among population means. All statistical analyses were performed using Statistica (1999).

Global analysis of song differences among the cryptic species of the carnea group was limited to nine (of 15) ingroup taxa for which complete acoustical data for 20 or more individuals existed. To visualize and clarify differences, a discriminant function analysis was applied to song features. In discriminant function analysis, strong correlations between variables will bias or even preclude an analysis, so we eliminated one of each pair of variables exhibiting high correlation coefficients $(r \geq 0.80)$. The feature retained was chosen for its lower correlations, on average, with the other variables. In the present analysis, 17 song variables yielded six 'least correlated' features (Table 4), which were then used to extract six multidimensional roots. Statistical differences in songs among the nine lacewing taxa were determined from the matrix of squared Mahalanobis distances generated by the discriminant function analysis, assuming à priori classification probabilities proportional to group sizes (Table 4).

Behavioral Tests. To test the responsiveness of $C c 2$ and $C c 4$ individuals to one another's recorded songs, each insect was presented with its own song type and the alternative song type in a paired design (Wells and Henry 1992a). For each of the two species, four different stimulus signals were prepared, each from a different male captured at a different geographical site to avoid pseudoreplication (Kroodsma 1989). Each stimulus signal consisted of a single, complete SRU recorded on cassette tape (Dolby off) at $25 \pm 1^{\circ} \mathrm{C}$. To prepare each SRU, the original tape recording was digitized, band-pass filtered to remove frequencies below $12 \mathrm{~Hz}$ (the DC component) and above $200 \mathrm{~Hz}$ and normalized to create signals of equal maximum amplitude $( \pm 5 \mathrm{~V})$. Stimulus signals were played back at constant volume to the experimental animal using a Labworks (Costa Mesa, CA) ET-132-203 electronic shaker to vibrate the experimental arena from beneath. Temporal and frequency characteristics of those songs are given in Table 5.

Responsiveness was tested in one male and one female of Cc2 collected in mid December 1999 in Vouvray, central France; one male and two females of Cc2 collected on 21 February, 2000 in Buckingham Palace Gardens, London, UK; and three males and one female of Cc4 collected in late October 1999 near Edinburgh, Scotland, UK. All experimental animals were maintained at long-day photoperiod until sexually receptive. Each was then tested against four independently selected pairs of stimulus signals, consisting of one song (SRU) from $C c 2$ and the other from

Table 5. Values of the features (see Figs. 1 and 3 ) of songs recorded as stimulus signals for Cc2 'slow-motorboat' and Cc4 'motorboat' from Europe

\begin{tabular}{|c|c|c|c|c|c|c|c|c|c|c|c|}
\hline & \multicolumn{3}{|c|}{ Mid-volley Frequencies, $\mathrm{Hz}$} & \multicolumn{6}{|c|}{ Time measures of volleys, milliseconds } & \multicolumn{2}{|c|}{ SRU features } \\
\hline & \multirow{2}{*}{$\begin{array}{c}\text { Start } \\
\text { of SRU }\end{array}$} & \multirow{2}{*}{$\begin{array}{l}\text { Middle } \\
\text { of SRU }\end{array}$} & \multirow{2}{*}{$\begin{array}{c}\text { End } \\
\text { of SRU }\end{array}$} & \multicolumn{2}{|c|}{ Start of SRU } & \multicolumn{2}{|c|}{ Middle of SRU } & \multicolumn{2}{|c|}{ End of SRU } & \multirow{2}{*}{$\begin{array}{c}\text { Duration, } \\
\text { seconds }\end{array}$} & \multirow{2}{*}{$\begin{array}{l}\text { No. of } \\
\text { volleys }\end{array}$} \\
\hline & & & & Duration & Period & Duration & Period & Duration & Period & & \\
\hline Cc2 ठิ 2a (Ticino, Alps) & 47.48 & 71.94 & 44.6 & 227 & 330 & 244 & 298 & 291 & 336 & 9.31 & 29 \\
\hline Cc2 ठ̊ $2 \mathrm{~b}$ (Ticino, Alps) & 54.23 & 82.39 & 54.23 & 210 & 337 & 195 & 287 & 215 & 289 & 12.27 & 42 \\
\hline$C c 2$ o $2 \mathrm{c}$ (Geneva) & 59.17 & 80.83 & 62.5 & 208 & 306 & 209 & 291 & 249 & 311 & 16.58 & 55 \\
\hline$C c 2$ đ $2 \mathrm{~d}$ (France) & 43.44 & 68.03 & 50 & 220 & 306 & 215 & 280 & 229 & 293 & 7.4 & 24 \\
\hline Cc4 ơ 4a (Ticino, Alps) & 47.92 & 70.14 & 79.86 & 128 & 163 & 122 & 144 & 79 & 97 & 7.03 & 54 \\
\hline Cc4 ơ $4 \mathrm{~b}$ (England) & 64.75 & 74.59 & 84.43 & 110 & 147 & 125 & 154 & 112 & 133 & 4.56 & 31 \\
\hline Cc4 ô 4c (England) & 44.44 & 74.07 & 74.07 & 109 & 167 & 124 & 148 & 105 & 137 & 9.1 & 62 \\
\hline$C c 4$ oे $4 \mathrm{~d}$ (Finland) & 59.85 & 71.97 & 82.58 & 105 & 134 & 130 & 149 & 86 & 105 & 7.6 & 59 \\
\hline
\end{tabular}

These recorded signals were used in the behavioral tests described in the text and Table 6 . 
Table 6. Mean number of dueting responses (SRUs) given by individuals of $C c 2$ and $C c 4$ to stimulus signals $(n=$ independent trials) prepared from the songs of four different individuals of $\mathrm{Cc2}$ and four of $\mathrm{Cc4}($ coded as in Table 5)

\begin{tabular}{|c|c|c|c|}
\hline & & $\begin{array}{l}\text { Responses } \\
\text { to five } \\
C c 2 \text { songs }\end{array}$ & $\begin{array}{c}\text { Responses } \\
\text { to five } \\
\text { Cc4 songs }\end{array}$ \\
\hline$C c 2$ ○े 1 & (France), set 2b_4a $(n=2)$ & 5 & 0 \\
\hline$C c 2$ के 1 & (France), set 2c_4d $(n=2)$ & 5 & 0 \\
\hline$C c 2$ oै 1 & (France), set 2d_4c $(n=2)$ & 5 & 0 \\
\hline$C c 2$ oे 1 & (France), set 2a_4b $(n=2)$ & 5 & 0 \\
\hline$C c 2$ के 2 & (London), set 2b_4d $(n=2)$ & 5 & 0 \\
\hline$C c 2$ ○े 2 & (London), set 2c_4b $(n=2)$ & 5 & 0 \\
\hline$C c 2$ ठ 2 & (London), set 2a_4c $(n=2)$ & 5 & 0 \\
\hline$C c 2$ 우 1 & (France), set 2c_4c $(n=2)$ & 4 & 0 \\
\hline$C c 2$ 우 1 & (France), set 2d_4b $(n=2)$ & 1.5 & 0 \\
\hline$C c 2$ 우 1 & (France), set 2a_4a $(n=2)$ & 4.5 & 0 \\
\hline$C c 2$ 우 1 & (France), set 2b_4d $(n=2)$ & 5 & 0 \\
\hline$C c 2$ 우 2 & (London), set 2d_4b $(n=2)$ & 4 & 0 \\
\hline$C c 2$ 우 2 & (London), set 2a_4a $(n=2)$ & 5 & 0 \\
\hline Cc2 우 2 & (London), set 2c_4c $(n=2)$ & 5 & 0 \\
\hline$C c 2$ 우 2 & (London), set 2b_4d $(n=2)$ & 5 & 0 \\
\hline$C c 2$ ㅇ 3 & (London), set 2c_4d $(n=2)$ & 5 & 0 \\
\hline$C c 2$ 우 3 & (London), set 2a_4b $(n=2)$ & 4.5 & 0 \\
\hline$C c 2$ ㅇ 3 & (London), set 2b_4a $(n=2)$ & 5 & 0 \\
\hline Cc2 오 3 & (London), set 2d_4c $(n=2)$ & 5 & 0 \\
\hline $\operatorname{Cc} 4$ oै 1 & (Scotland), set 2c_4c $(n=2)$ & 0 & 5 \\
\hline$C c 4$ के 1 & (Scotland), set 2c_4d $(n=2)$ & 0 & 5 \\
\hline$C c 4$ के 1 & (Scotland), set 2d_4a $(n=2)$ & 0 & 5 \\
\hline$C c 4$ ठै 1 & (Scotland), set 2a_4d $(n=2)$ & 0 & 5 \\
\hline $\mathrm{Cc} 4$ ठै 2 & (Scotland), set 2a_4a $(n=2)$ & 0 & 2.5 \\
\hline $\mathrm{Cc} 4$ ठै 2 & (Scotland), set 2c_4b $(n=1)$ & 0 & 2 \\
\hline Cc4 oै 3 & (Scotland), set 2a_4d $(n=2)$ & 0 & 5 \\
\hline Cc4 ô 3 & (Scotland), set 2d_4b $(n=2)$ & 0 & 5 \\
\hline Cc4 of 3 & (Scotland), set 2c_4a $(n=2)$ & 0 & 4 \\
\hline$C c 4$ o 3 & (Scotland), set 2b_4c $(n=2)$ & 0 & 5 \\
\hline Cc4 우 1 & (Scotland), set 2b_4c $(n=2)$ & 0 & 2.5 \\
\hline $\mathrm{Cc} 4 \stackrel{+}{1}$ & (Scotland), set 2a_4a $(n=2)$ & 0 & 5 \\
\hline $\mathrm{Cc} 4$ 우 1 & (Scotland), set 2c_4b $(n=2)$ & 0 & 4 \\
\hline $\mathrm{Cc} 4$ 우 1 & $($ Scotland $)$, set $2 \mathrm{~d} \_4 \mathrm{~d}(n=2)$ & 0 & 3 \\
\hline
\end{tabular}

Each stimulus signal consisted of five replicates of one SRU; each stimulus signal set was a different combination of two stimulus signals randomly paired from the pool of eight SRUs. To be counted as a response, an SRU had to be produced immediately after a stimulus signal. Because no individuals responded to heterospecific signals, statistical tests were not performed. France = Vouvray; Scotland $=$ Edinburgh.

Cc4. Each pair of signals was presented twice, randomized by coin toss as to order of presentation and in both possible orders, yielding a target of eight paired tests per animal (Table 6). The tendency of the test animal to duet with the playback song was assessed by counting the number of correct responses (SRUs) the insect made to five replicates of each stimulus signal. Replicates were presented either immediately after a positive response by an insect or after a 5-s pause if the insect gave no response. After a signal of one song type had been presented, we waited until the individual stopped tremulating before playing five replicates of the second type of song. Once this first pair (set) of song presentations was completed, each song type was presented a second time, with the order of presentation reversed. The entire experimental sequence was then repeated three more times using a different set of stimulus signals, each chosen at random from among the 16 possible combinations of signals but with the requirement that no stimulus signal be used in more than one experimental sequence for a given individual.

We used the mean number of responses to each song type given by each individual to a specific pair of stimulus signals as a single data point in our analysis. For all experiments, paired $t$-tests were performed to compare means.

Adult Morphology. Forty individuals of Cc2 and 39 of $C c 4$, identified acoustically, were examined for external morphological features that might vary between species or among populations of each species across its geographic range. Localities included Carcès, France (4 Cc2); Vouvray, France (3Cc2, 1 Cc4); Cavaglio/Traffiume, Italy (14 Cc2, 4 Cc4); Ticino, Switzerland ( 3 Cc2, 6 Cc4); Geneva, Switzerland (8 Cc2); Zürich, Switzerland (1 Cc2); Berchtesgaden, Germany (3 Cc4); Brückl, Austria (1 Cc4); Banovce, Slovak Republic (3 Cc4); Devon, England (2 Cc4); London, England ( 7 Cc2); Edinburgh, Scotland (14 Cc4); Tammela, Finland (2 Cc4); and Belgorod, Russia ( $3 \mathrm{Cc} 4$ ). These sites were a geographically representative subset of the localities listed in Table 1 .

Whenever possible, song-determined adults were examined for the states of 19 characters. These included ground color of (1) body and (2) palps; presence, extent and color of markings on (3) stipes, (4) gena, (5) clypeus, (6) frons, and (7) postoccipital region; (8) relative abundance and distribution of black and blond setae on pronotum; (9) relative size of basal dilation of tarsal claw expressed as a ratio (see below); (10) extent to which fore wing is rounded or tapered at apex; (11) relative width of fore wing expressed as the ratio of length to breadth at widest point; (12) presence or absence of black markings on wing veins; (13) length and color of costal setae; (14) length of abdominal setae; (15) presence of predominantly black or blond setae on the three distal abdominal sternites; (16) shape of genital 'lip' and 'chin' at apex of sternite $8+9$ in males expressed as two ratios (see below); (17) length and color of setae clothing genital lip; (18) relative size of medial lobe (acumen) of tignum in male genitalia expressed as the ratio of length of arm of tignum to length of acumen (see Fig. 9 in Henry et al. 1999b); and (19) presence or absence of dark brown stripe on pleural membrane of second abdominal segment.

The shape of the pretarsal claw was assessed by removing one metathoracic leg, mounting it in Euparal on a microscope slide, splaying the claws by flattening the pretarsus beneath the cover slip, and viewing and drawing one or both claws using a camera lucida. Two different ratios were then taken from the drawings (Fig. 4). One ratio (method 1 ) compares line segments drawn between points $\mathrm{A}, \mathrm{B}$, and $\mathrm{D}$ and takes the form AB/BD (Brooks 1994, Thierry et al. 1998). The other ratio (method 2, Henry et al. 1999b) attempts to avoid error due to wear of the claw tip by taking the ratio of total claw width $(\mathrm{Wt})$ to the amount of its basal dilation (Wd). The methods were compared with one another by (1) regressing one set of measurements against the other and testing the significance of the correlation and (2) calculating coef- 


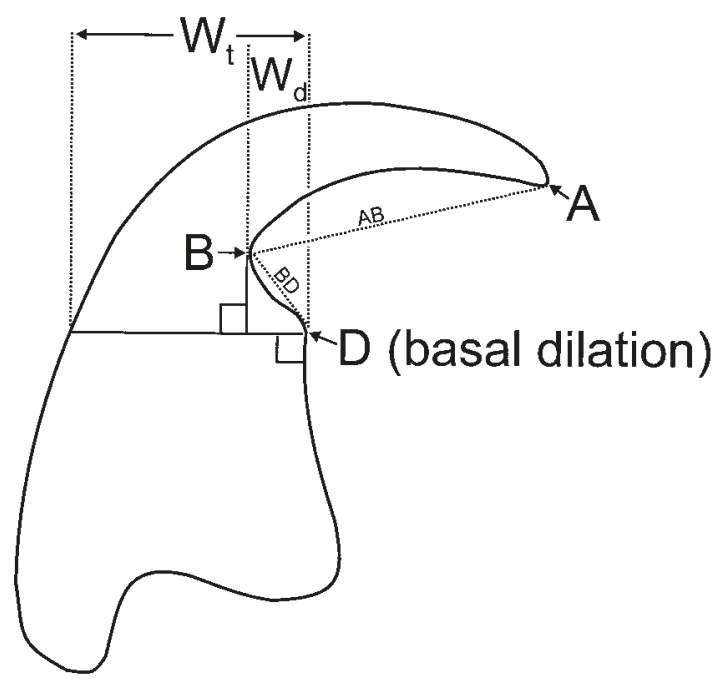

Fig. 4. Pretarsal claw of a lacewing, illustrating line segments $\mathrm{AB}, \mathrm{BD}, \mathrm{Wt}$, and $\mathrm{Wd}$ used for calculating a ratio describing the basal dilation of the claw. Specifically, method 1 calculates the ratio $\mathrm{AB} \div \mathrm{BD}$, and method 2 calculates the ratio $\mathrm{Wt} \div \mathrm{Wd}$ (see text).

ficients of variation for each of the two sets of measurements generated by the methods. To assess misclassification of $C c 2$ versus $C c 4$ based on claw measurements alone, a discriminant function analysis was performed comparing the two song species with respect to claw ratios (method 1) obtained strictly from song-determined specimens.

To determine the shape of the external genital area of the male abdomen, the tip of the abdomen was removed and placed in glycerol, then viewed, and drawn through a binocular microscope at $100 \times$ magnification. Measurements of 'lip' and 'chin' dimensions were taken from the drawings (Fig. 5, line segments defined by points A through $\mathrm{G}$ ). The ratio $\mathrm{AC} / \mathrm{AB}$ reflected the relative prominence of the chin, while that of DE/FG was used to describe the shape of the lip. Setal color was judged to be black, blond, or mixed by examination with reflected light under a dissecting microscope. Internal genitalia of selected males were dissected, stained, mounted, and measured using established techniques (Bram and Bickley 1963, Brooks 1994).

We also examined preserved specimens conforming to the range of morphological characteristics encompassed by $C c 2$ and $C c 4$ but not identified acoustically. These included (1) six recently collected specimens judged to match either a 'Cc2 morphotype' (three from Buckingham Palace Gardens, London, and two from Vouvray, France) or a 'Cc4 morphotype' (one from the Palace gardens); (2) 10 specimens in the Stephens Collection of the BMNH, containing the female lectotypes of C. carnea and C. affinis, a male and a female labeled 'C. alba', and a small type series of seven individuals of unspecified diagnosis; and (3) 140 specimens labeled 'C. carnea' from the BMNH British collection. Each insect in the Buckingham Palace/
Cc2, London
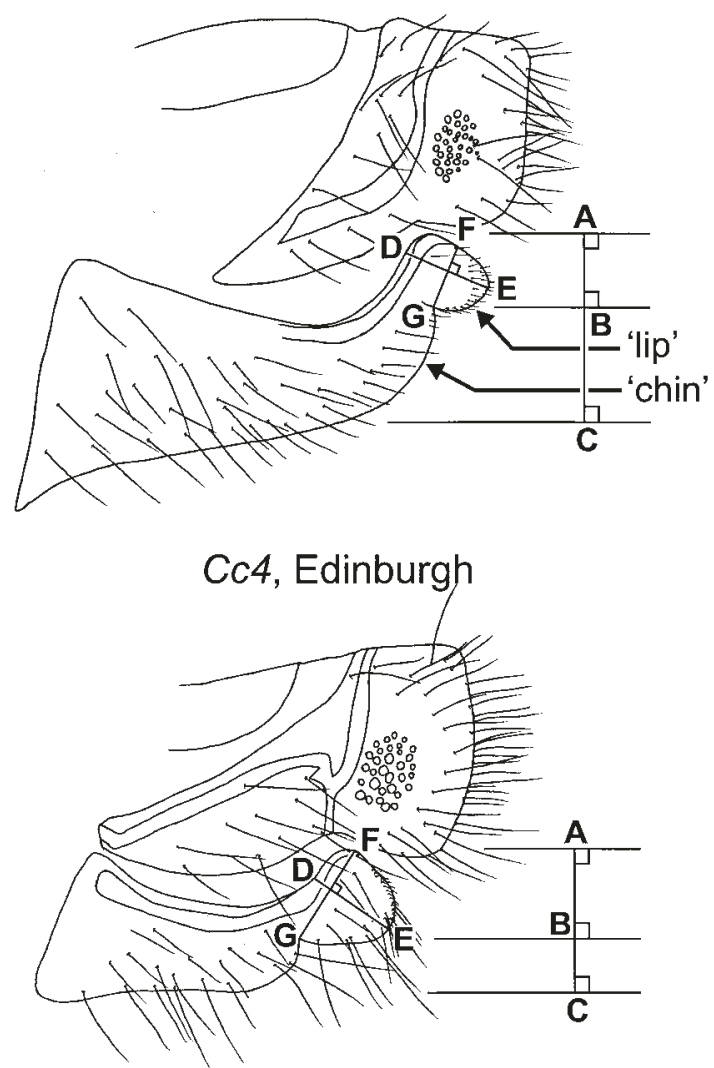

Fig. 5. Terminus of male abdomen of Cc2 (C. pallida) and $C c 4$ (C. carnea), illustrating line segments AC, AB, DE, and FG used for calculating the ratios describing the shape of the genital 'lip' and 'chin'. The lip was judged to be narrow and not protruding if $\mathrm{DE}>\mathrm{FG}$ and the chin broad (strong) if $\mathrm{AB}<\mathrm{BC}$

Vouvray collection and the Stephens Collection was carefully examined for the color of its abdominal setae, the extent of markings on the stipes, the width of the basal dilation of its hind claw (or mesothoracic claws if, as in the lectotype of C. carnea, the hind claws were missing), and the shape of the genital lip (males only). All 140 specimens in the BMNH British collection were then segregated into classes based on abdominal setal color (blond, black, or mixed). Then, to determine the ratio of $C c 2$ to $C c 4$ morphotypes in that collection, we recorded the basal claw dimensions of 11 specimens with blond setae and 10 specimens with black setae, using both methods 1 and 2 . The genital lip of four male specimens with blond sternal setae was also examined and its shape measured and assessed.

Larval Morphology. We examined a total of 74 firstinstar, 124 second-instar, and 142 third-instar larvae from eight populations of $C c 2$ 'slow-motorboat' and 155 first-instar, 202 second-instar, and 201 third-instar larvae from 13 populations of $C c 4$ 'motorboat'. These populations represented most of the major regions 
from which the two song species had been collected (Table 1), with the exception of the United Kingdom (both $C c 2$ and $C c 4$ missing) and south-central France (Cc4 missing). Specific geographic areas and sample sizes ( $n=$ first, second, third instars) included the Ticino region of the Alps of southern Switzerland and northern Italy (Cc2: $n=64,100,90 ; C c 4: n=75,49,53)$; the Alps of northern Switzerland and southern Germany (Cc2: $n=0,13,29$; Cc4: $n=15,37,54)$; central and southern France (Cc2: $n=9,11,23$; $C c 4$ : none); Belgium (Cc2: none; Cc4: $n=2,14,5)$; eastern Europe (Cc2: none; Cc4: $n=27,18,21$ ); and southern Finland (Cc2: none; $C c 4: n=36,84,68)$. When possible, larvae were boiled in $100 \mathrm{cc}$ distilled water with a drop of liquid detergent, allowed to cool, and then transferred to $70 \%$ ethanol $+5 \%$ glycerol $+25 \%$ distilled water for storage. Some previously collected larvae had unavoidably been placed in $70 \%$ ethanol, resulting in greater deterioration. Larvae were examined at $50 \times$ magnification. Representative individuals were selected and illustrated.

\section{Results}

Biogeography. Each of the six Eurasian song species of the carnea group was broadly distributed. The species with the largest range was $C$. lucasina, which was collected from the Canary Islands to Cyprus and from northern Africa to northern Scotland (Henry et al. 1996). Cc4 'motorboat' was also very widely distributed but exhibited a northerly bias. It was found as far south as the southern Alps but ranged northward to the northernmost islands of the United Kingdom and southern Fennoscandia and eastward at least to west/ central Russia (Table 1; Fig. 2). The song species $C$. mediterranea and $C c 3$ 'Maltese' shared a more southerly, circum-Mediterranean distribution, except for the northeastward extension of $C$. mediterranea into eastern Europe (Henry et al. 1999b, Henry et al. 2001) and the westward extension of $\mathrm{Cc} 3$ to the Açores archipelago $2,000 \mathrm{~km}$ at sea (specimens courtesy of Ms. Maria da Anunciacao Mateus Ventura, August 2000). Cc5 'generator' was a Middle Eastern/Asian species whose western range limit appeared to be the extreme eastern margin of the Mediterranean Sea (Henry et al. 2001). Finally, Cc2 'slow-motorboat' was central European, occurring in an area bounded by central Spain to the west, England to the north, and Greece and Hungary to the south and east (Table 1; Fig. 2). Unlike cold-tolerant $C c 4, C c 2$ was limited to elevations below 1,000 $\mathrm{m}$ in the Alps and was not found north of Berlin in mainland Europe.

Three song species, C. lucasina, Cc2 'slow-motorboat', and Cc4 'motorboat', were confirmed by song phenotype as present in the United Kingdom. Chrysoperla lucasina and Cc4 occurred throughout the British Isles and could be quite abundant seasonally. Cc2, previously not found in the United Kingdom, was finally collected in February 2000 from Buckingham Palace Gardens, London and again in November and December 2000 from Silwood Park, $40 \mathrm{~km}$ west of London. None of the three remaining song species was found sufficiently far north in mainland Europe to support any suspicion that their ranges might extend across the English Channel.

Ecophysiology. In temperate regions, all species of Chrysoperla overwinter as diapausing adults; in fact, this is a diagnostic autapomorphy of the genus (Séméria 1977). However, species within Chrysoperla vary with respect to the color changes they experience in response to temperature and photoperiod during winter diapause: some remain green, while others turn mixtures of yellow, brown, orange, and red (Tauber and Tauber 1986, Thierry et al. 1995). The type of $C$. carnea was described by Stephens (1835, p. 103) as exhibiting a "bright rosy-red, or flesh-color" ground color with additional yellow and red markings, indicating its membership in a taxon that changes color. According to observations of our own and of others (Thierry et al. 1995, Henry et al. 1996), British and mainland European representatives of C. lucasina remained bright green through all seasons, while adults of both $C c 2$ and $C c 4$ underwent marked autumnal change to yellowish-brown ( $C c 2$ ) and reddish-brown $(C c 4)$. If present-day ranges are representative of the past, then it is clear that only $C c 2$ or $C c 4$ could be the 'true carnea' of Stephens. We will therefore limit discussion to those two song species.

Song Phenotype. As mentioned earlier, the songs (=SRUs) of both $C c 2$ and $C c 4$ are long, relatively complex signals consisting of many short, similar volleys (syllables) of abdominal vibration. However, the two species differed with respect to nearly every song feature, in both the time and frequency domains. Each also differed significantly from every other described song species in Eurasia.

Cc2 'Slow-Motorboat'. Results of ANOVAs (not shown) indicated that equivalent levels of variation existed in $C c 2$ among the songs of a single individual and among the individual averages of any given population of individuals. Within single individuals, the coefficients of variation averaged $9.75 \%$ for six major temporal song features and $7.08 \%$ for all nine frequency features, while between individuals in a population, mean coefficients of variation measured 11.52 and $12.12 \%$, respectively. Therefore, it was valid to compare sex-delimited or geographic populations using individual averages as has been done in previous studies of song variation in lacewing species (Henry and Wells 1990).

Adult males and females of $C c 2$ produced a single type of song (=SRU), which was used both in solitary calling and dueting. The SRU was multisyllabic, consisting of a 3.4- to 90-s series of 12-246 short, similar volleys separated from each other by very short intervals (Fig. 1; Table 2). Volleys averaged $\approx 194 \mathrm{~ms}$ in length at the beginning of the SRU, gradually increasing to $231 \mathrm{~ms}$ by its end. Volley period first decreased and then increased over the course of the SRU, starting at $\approx 313 \mathrm{~ms}$, declining to $290 \mathrm{~ms}$, then rising at the end of the song to $329 \mathrm{~ms}$. Although quite short, each volley nonetheless exhibited internal changes in carrier frequency, such that the frequency at the midpoint of each volley was $10-20 \mathrm{~Hz}$ higher than at the 
start and end of the volley (Fig. 3). The mid-volley reference frequency increased during the first six or seven volleys of the SRU from $\approx 53 \mathrm{~Hz}$ to an average maximum of $77 \mathrm{~Hz}$, and then decreased steadily to an average minimum of $50 \mathrm{~Hz}$ at the end of the SRU (Table 2; Fig. 1). Each SRU was also characterized by a progressive increase and decrease in intensity that roughly mirrored the rise and fall in volley carrier frequency (Fig. 1). Another notable feature of the Cc2 song was sharp, brief striking of the substrate by the moving abdomen at the start and end of each volley, particularly during the second two-thirds of each SRU (Fig. 1, spikes). Dueting was of the 'polite' type, seen in some other lacewings with multisyllabic SRUs (e.g., C. mediterranea, Henry et al. 1999b). In this type of duet, each partner answers the other only after an SRU has been completed.

Males and females were similar but not identical with respect to the 17 features measured (Table 2, asterisks: 11 of 17 shown). Females generally displayed longer SRUs than males, showed a slightly greater range of frequency modulation over the course of each SRU, and attained significantly higher peak frequencies at mid-SRU $(\approx 81 \mathrm{~Hz}$ in females versus $75 \mathrm{~Hz}$ in males). However, sex differences were judged small enough to warrant pooling all individuals in other comparisons.

Populations of Cc2 from England, from north of the Alps and from south of the Alps (Fig. 2) were compared with respect to measurements of all song features (analysis not shown). Differences were very slight and statistically significant only for the three 'mid-SRU' frequency measures, which were consistently elevated in British specimens. That small effect was probably a simple consequence of sex bias (see preceding paragraph): five of the seven individuals from England were females (sex ratio $=0.71$ ), whereas our nonBritish samples consisted largely of males $($ ratio $=0.25)$. For reasons that are less clear, the six individuals from south-central France also differed slightly but significantly in possessing somewhat shorter, more closely spaced volleys than the other populations.

Cc4 'Motorboat'. As in Cc2, within- versus amongindividual variation was similar (ANOVA, not shown), validating the use of individual averages in statistical comparisons. Within single individuals of $\mathrm{Cc4}$, the coefficients of variation averaged $9.04 \%$ for six major temporal song features and $4.52 \%$ for the nine frequency features, while between individuals in a population, mean coefficients of variation measured 11.60 and $8.92 \%$, respectively. Other than in length (see below), male and female songs of $C c 4$ were indistinguishable (Table 2). Consequently, data from individuals of both sexes were pooled in most analyses.

Two distinct types of songs characterized Cc4, although only males produced both types (Fig. 1). We interpreted the shorter of the two as a male calling song (Ewing 1989) or possibly an advertisement song (Wells 1977, Gerhardt 1994), which was often exchanged between two males in a duet. The long song was probably a courtship song (Ewing 1989, Bailey
1991), always used by both males and females during heterosexual duets, but occasionally delivered spontaneously by solitary individuals. The long song was exchanged 'politely' between two individuals of different sex, that is, without interruption of one partner by the other.

The SRU of the short (male calling) song was multisyllabic, consisting of a 2.5-11 s series of 21-83 $($ mean $=47)$ very short, similar volleys separated from each other by very short intervals (Fig. 1; Table 3). Volleys averaged $114 \mathrm{~ms}$ in length at the beginning of the SRU, gradually decreasing to $97 \mathrm{~ms}$ by its end. Volley period also decreased during the course of the SRU from 155 to $128 \mathrm{~ms}$. Although extremely short, each volley exhibited internal changes in carrier frequency, such that the frequency at the end of each volley was 10 to $20 \mathrm{~Hz}$ higher than at its start (Fig. 3). The mid-volley reference frequency increased in a predictable 'flipped sigmoid' manner during the course of the SRU, from $\approx 47$ to $75 \mathrm{~Hz}$ (Table 3; Fig. 1). Each SRU attained maximum amplitude at its midpoint (Fig. 1).

Long songs were trains of 100 or more nearly identical volleys lasting up to several minutes (Fig. 1). Volleys at the start of a long SRU were slightly but significantly longer than those at the start of short songs, averaging $128 \mathrm{~ms}$ in length and $174 \mathrm{~ms}$ in period (Table 2). In every other respect, short and long songs were identical. Long songs did not appear to show the 'flipped sigmoid' changes in mid-volley frequency that were so characteristic of male short songs. Instead, volley carrier frequency quickly rose to a constant, higher value, and sometimes increased further at the very end of the SRU. Heterosexual partners used long songs nearly exclusively when dueting.

Populations of $C c 4$ from four geographic areas of Europe (Fig. 2), specified as the United Kingtom, Fennoscandia, eastern Europe, and the Alps, were compared with respect to measurements of all song features. Except for SRU duration and SRU volley number, which were strongly influenced by sample size and sex ratio, the populations were acoustically indistinguishable (ANOVA, $F=0.35-2.77, \mathrm{df}=61-67$; Scheffé's post hoc tests not shown).

Comparison of Songs of Cc2 and Cc4. The two song species, $C c 2$ and $C c 4$, differed significantly from one another with respect to every song feature except the hypervariable traits SRU duration and SRU volley number (paired $t$-tests, $t=2.8-36.5, \mathrm{df}=91-112$; tests not shown). Specifically, the song of Cc4, compared with $C c 2$, exhibited shorter and more closely spaced volleys characterized by a distinctly different pattern of within- and between-volley frequency modulation (Tables 2 and 3; Figs. 1 and 3). We noted, however, that the average absolute highest frequency attained in a song-approximately $77 \mathrm{~Hz}$ at $25^{\circ} \mathrm{C}$-was not significantly different between the two song species (paired $t$-test, $t=1.98, \mathrm{df}=112$ ).

Global Song Comparisons. When the songs of Cc2 and $C c 4$ were included with other cryptic song species of the carnea-group in a discriminant function analysis, the magnitude of the differences between the two 


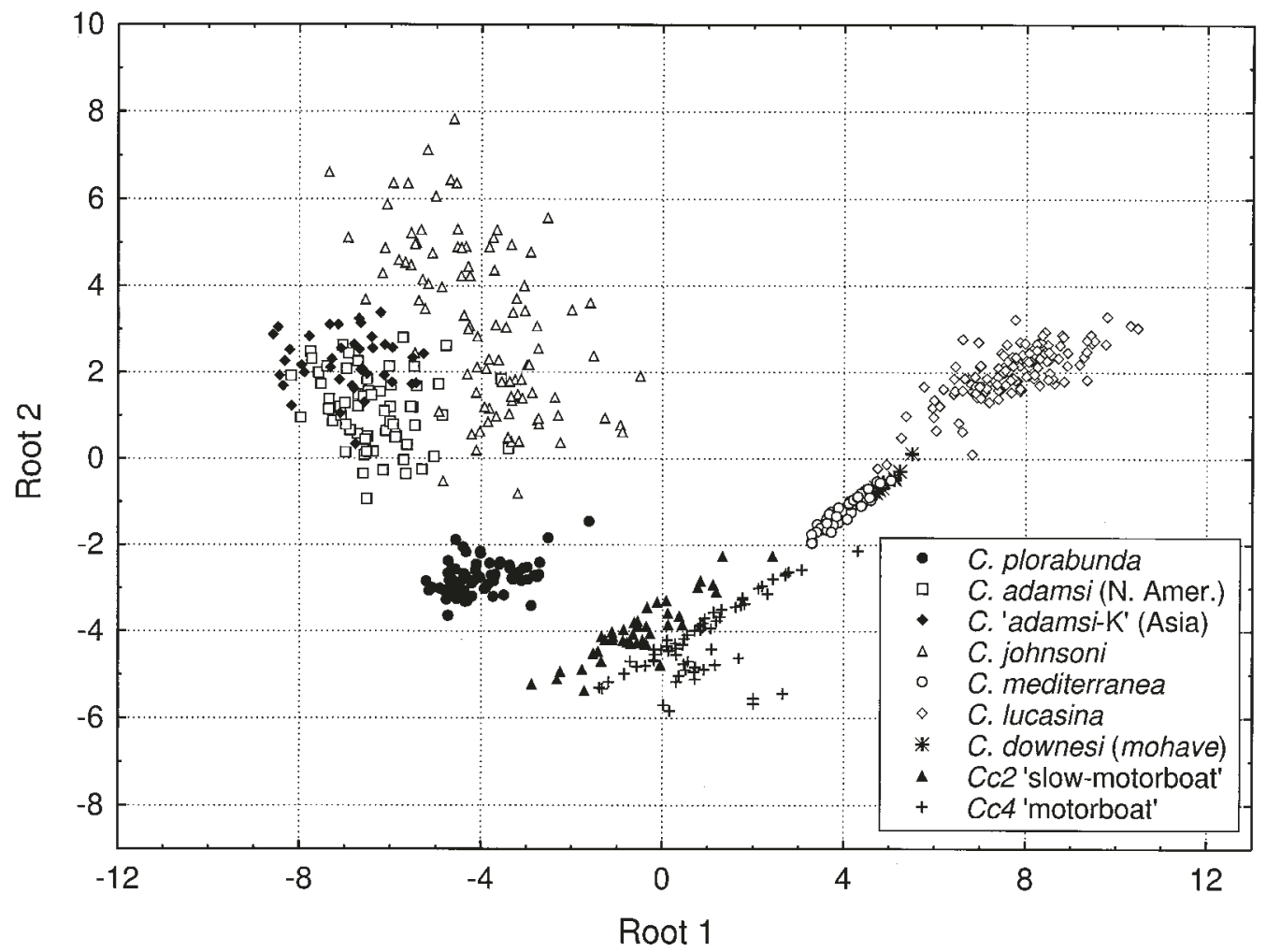

Fig. 6. Scatterplot of the first two roots of a discriminant function analysis of six 'least-correlated' measurements of the songs of nine distinct song species of the carnea group. Each data point represents a single individual, coded by species. Song features used in the analysis are specified in the footnote for Table 4.

species was small but highly significant (Table 4; Fig. $6)$. In fact, all nine song species used in the analysis were significantly different from one another in all pairwise comparisons based on the matrix of squared Mahalanobis distances (Table 4). The two most-similar species pairs were $C$. mediterranea/C. downesi (mohave) and C. 'adamsi-K' (Asia)/C. adamsi, both of which were comparisons between completely allopatric taxa living on different continents (Henry et al. 1999a)

Behavioral Tests. When sexually receptive adults of either $C c 2$ 'slow-motorboat' or Cc4 'motorboat' were given a choice of their own recorded song versus that of the other song species, they responded by dueting only to their own song (Table 6). This result was obtained regardless of the sex of the experimental animal, the order of signal presentation, or the source (individual and geographic origin) of the stimulus signal. Males of Cc4 always answered stimulus signals with short (calling) songs, while the single tested female responded using long (courtship) songs. Although Cc2 did not possess two distinct types of songs, two tested males of that species also responded to all conspecific stimulus signals with relatively short songs (12-30 volleys), whereas the female gave longer responses (25-87 volleys). Because no individuals of either song species responded to heterospecific signals, statistical tests were not performed on the data.
Ecology. The recognition of song species within the carnea group of Chrysoperla is changing our understanding of their ecology. What had previously been interpreted as ecotypic variation within a single species (polymorphism) is now seen to be consistent differences among distinct, reproductively isolated species. Specific habitat associations are known to exist in Chrysoperla, but documentation of such in the carnea group has been impeded by taxonomic uncertainty. Results from collecting records of song-determined individuals and from examination of morphotypes collected in transects, sticky traps, and comprehensive faunal surveys (Duelli 1988; and D.P., unpublished data) revealed significant ecological differences between $C c 2$ and $C c 4$. During the growing season, $C c 2$ was most abundant in the trees and tall shrubs at the edges of forests or in urban areas (also reported by Thierry et al. 1998 for 'C. carnea,' their name for the $C c 2$ morphotype). In contrast, $C c 4$ was found during most of the summer on herbaceous vegetation and tall grasses in open fields, although lateinstar larvae could also be collected from trees and shrubs. Of the two, only $C c 4$ was collected from croplands, making that species the ecological analog of $C$. plorabunda in North America. In central and southern Europe, Cc4 coexisted in agricultural fields with another song species, C. lucasina, which typically com- 
Table 7. The state of diagnostic morphological features in song-determined and morphotype-determined specimens of $C c 2$ and $C c 4$

\begin{tabular}{|c|c|c|c|c|c|c|c|c|c|c|}
\hline \multirow{2}{*}{ Taxon or Specimen } & \multirow{2}{*}{ Region } & \multirow{2}{*}{$N$} & \multirow{2}{*}{$\begin{array}{c}\text { Sex } \\
\text { or } \\
\text { ratio }\end{array}$} & \multicolumn{2}{|c|}{ Color of abdominal setae } & \multicolumn{2}{|c|}{ Color of stipes } & \multicolumn{2}{|c|}{$\begin{array}{l}\text { Type of } \\
\text { lip/chin }\end{array}$} & \multirow{2}{*}{$\begin{array}{l}\text { Claw shape, } \\
\mathrm{AB} / \mathrm{BD} \text { ratio }\end{array}$} \\
\hline & & & & $\begin{array}{l}<50 \% \\
\text { black }\end{array}$ & $\begin{array}{l}\geq 50 \% \\
\text { black }\end{array}$ & $\begin{array}{l}<50 \% \\
\text { black }\end{array}$ & $\begin{array}{l}\geq 50 \% \\
\text { black }\end{array}$ & $C c 2$ & $C c 4$ & \\
\hline \multirow[t]{3}{*}{$C c 2$, det by song } & France & 7 & 0.71 & $n=7$ & $n=0$ & $n=7$ & $n=0$ & $n=2$ & $n=0$ & $2.02 \pm 0.03$ \\
\hline & Alps & 26 & 0.46 & $n=26$ & $n=0$ & $n=26$ & $n=0$ & $n=14$ & $n=0$ & $1.95 \pm 0.17$ \\
\hline & UK & 7 & 0.71 & $n=6$ & $n=1$ & $n=7$ & $n=0$ & $n=2$ & $n=0$ & $1.84 \pm 0.11$ \\
\hline \multirow{2}{*}{$C c 2$, det by morphotype } & France & 2 & 0.00 & $n=2$ & $n=0$ & $n=2$ & $n=0$ & $n=2$ & $n=0$ & $1.84 \pm 0.20$ \\
\hline & London & 3 & 0.00 & $n=3$ & $n=0$ & $n=3$ & $n=0$ & $n=3$ & $n=0$ & $1.82 \pm 0.04$ \\
\hline \multirow[t]{4}{*}{$C c 4$, det by song } & France & 1 & $\mathrm{~F}$ & & All black & & Half black & & - & 2.5 \\
\hline & Alps & 14 & 0.31 & $n=4$ & $n=9$ & $n=3$ & $n=10$ & $n=0$ & $n=9$ & $2.15 \pm 0.13$ \\
\hline & UK & 16 & 0.53 & $n=2$ & $n=13$ & $n=3$ & $n=12$ & $n=0$ & $n=7$ & $2.33 \pm 0.18$ \\
\hline & N/E Eur. & 8 & 0.25 & $n=0$ & $n=8$ & $n=0$ & $n=8$ & $n=0$ & $n=6$ & $2.23 \pm 0.09$ \\
\hline Cc4, mphtype & London & 1 & M & & All black & & $3 / 4$ black & & J & 2 \\
\hline affinis Ltype & London & 1 & $\mathrm{~F}$ & & All black & & All black & & & 2.5 \\
\hline carnea Ltype & London & 1 & $\mathrm{~F}$ & All blond & & $3 / 4$ blond & & & & 2.11 \\
\hline 'alba' 1 & London & 1 & M & All blond & & $2 / 3$ blond & & & J & 2.41 \\
\hline ‘alba’ 2 & London & 1 & $\mathrm{~F}$ & & All black & all blond & & & & Not measured \\
\hline Number 61 & London & 1 & $\mathrm{~F}$ & All blond & & & Faint black & & & Not measured \\
\hline Number 62 & London & 1 & M & & All black & & Half black & & $\checkmark$ & Not measured \\
\hline Red label & London & 1 & $\mathrm{~F}$ & & $3 / 4$ black & $3 / 4$ blond & & & & Not measured \\
\hline No ID & London & 1 & M & & 3/4 black & & Half black & & $\checkmark$ & Not measured \\
\hline abd eaten & London & 1 & M & & All black & $2 / 3$ bond & & & v & Not measured \\
\hline abd missing & London & 1 & $-?-$ & & $-?-$ & & All black & & $-?-$ & Not measured \\
\hline
\end{tabular}

abd., abdomen; det, determined; N/E Eur., eastern Europe/Russia plus Finland; Ltype, lectotype; mphtype, morphotype.

prised $\approx 15-25 \%$ of the lacewings collected at each site (Duelli 2001).

Various collecting methods detected high daily rates of lacewing movement in the spring and fall. Based on careful assessment of morphology (see below), only $C c 4$ were found to be among the dispersers, indicating that $C c 4$, but not $C c 2$, moved large distances to and from overwintering sites in forests, forest edges, and buildings (Duelli 1986). Probably as a consequence of this migration, Cc4 appeared in large numbers at the lights of houses in late fall and winter (P.D., unpublished data). In the spring, before moving back to fields and croplands, individuals of $\mathrm{Cc} 4$ first visited early flowering trees such as Acer spp., where adults ate pollen. Eggs of both species appeared in April and May, after the spring mating period. $C c 4$ and northern populations of $C c 2$ oviposited eggs singly, whereas southern populations of $\mathrm{Cc} 2$ laid eggs in loosely organized groups, similar to those typical of C. mediterranea (Henry et al. 1999b). Two to three generations per year characterized both species in central and southern Europe, but in northern Europe Cc4 was univoltine.

Adult Morphology. We found no differences between $C c 2$ and $C c 4$ for most of the 19 morphological features examined in this study. Results below are therefore confined to the pigmentation of abdominal setae and maxillary stipes and to the shape of the pretarsal claw, genital lip, and genital chin.

Specimens Assigned by Song. Song-determined specimens of $\mathrm{Cc} 2$ differed, on average, from those of Cc4 in possessing blond abdominal setae, lightly marked stipes, large basal claw dilations (=lower $\mathrm{AB} / \mathrm{BD}$ ratios; see Fig. 4 and Table 7 ), and short, narrow genital lips (higher DE/FG ratios and lower $\mathrm{AB} / \mathrm{BC}$ ratios; see Fig. 5). However, a small percentage of each song species had the 'wrong' shade of setae and inappropriately marked stipes (Table 7), and their basal claw dimensions overlapped somewhat. Specifically, the range of basal dilation ratios $(\operatorname{method} 1)$ was 1.67-2.47 (1.67-2.14 excluding one outlier) for $C c 2$ $($ mean $=1.94, S D=0.15, n=39)$ and 1.67-2.76 $(1.98$ 2.76 excluding one outlier) for $C c 4$ (mean $=2.23, S D=$ $0.19, n=39)$. Despite overlap of ranges and inclusion of both outliers, this difference in means was highly significant $(t=-7.52$, df $=76, P \leq 0.000)$. Using method 1 claw measurements from strictly song-determined specimens, a discriminant function analysis misclassified only three of 39 individuals of Cc2 and five of 39 individuals of $C c 4$ (Wilkes' Lambda $=0.573$, $F=56.58 ; \mathrm{df}=1,76 ; P<0.000)$. The male genital lip on the abdomen showed the least overlap of any morphological feature. In $C c 2$ the lip was consistently small and narrow above a 'strong' chin $(\mathrm{DE}>\mathrm{FG}$, $\mathrm{AB}<\mathrm{BC}$ ), whereas in $\mathrm{Cc} 4$ it was always prominent and broad above a 'receding' chin $(\mathrm{DE}<\mathrm{FG}, \mathrm{AB}>$ $B C)$. Additionally, the setae covering the lip itself were short and fine in $C c 2$ but long and coarse in $C c 4$. More generally, the presence on the lip of black, coarse, long setae also did well at separating individuals of $C c 4$ from most individuals of $C$. lucasina, $C$. mediterranea, $C c 3$, and $C c 5$.

Specimens Assigned by Morphotype. Critical morphological characteristics of British and French specimens assigned to ' $C c 2$ ' by morphotype alone are shown in Table 7. As required by such assignment, ' $C c 2 \mathrm{~s}$ ' were discriminated from 'Cc4s' by blond setae, lightly marked stipes, and a small, narrow genital lip. Claw basal dilation ratio for ' $\mathrm{Cc2}$ ' ranged from 1.73 to $2.38($ mean $=1.83, S D=0.14, n=5)$, whereas the single ' $C c 4$ ' measured 2.00 (actually in the $C c 2$ range). Also shown in Table 7 are the same characters and measurements for the 10 specimens in the Stephens Collection. Pale setae and lightly marked stipes placed 
the $C$. carnea lectotype closer to the morphotype of $C c 2$ than to $C c 4$, but the mean of its claw measurements, 2.11, was clearly (if barely) assignable to $C c 4$ based on the results of the discriminant function analysis described earlier. The lectotype of C. affinis was a more typical $C c 4$, exhibiting dark setae, broadly marked stipes, and a large basal dilation ratio of 2.50 . The two specimens labeled ' $C$. alba', plus one of the unspecified individuals, showed a mix of $C c 2$ and $C c 4$ character states, whereas the rest of the type series conformed adequately to the morphotype of $\mathrm{Cc} 4$.

Of 140 specimens in the BMNH British Collection, 105 exhibited largely black sternal setae near the apex of the abdomen, 27 showed blond setae, and eight had a mixture of blond and black setae. Using randomly chosen individuals from each setal pure-color class and method 1 of measurement, the basal dilation ratio ranged from 2.05-2.49 $($ mean $=2.34, S D=0.13)$ for 10 'black' specimens and from 2.04-2.67 (mean $=2.29$, $S D=0.18$ ) for 11 'blond' ones. Those values were not significantly different from one another $(t=0.733$, $\mathrm{df}=19, P=0.473)$. Performing the same analysis using method 2 yielded similar results, with ratios ranging from 1.80-2.31 (mean $=1.98, S D=0.14)$ for the black population and from 1.66-2.09 (mean $=1.88, S D=$ $0.15)$ for the blond population $(t=1.632, \mathrm{df}=19, P=$ $0.119)$. Regressing method 1 measurements against method 2 measurements yielded correlation coefficients $(r)$ of 0.74 for the population with black setae and 0.73 for blond setae, both significant at $P<0.05$. Coefficients of variation were $5.58 \%$ (black) and $8.07 \%$ (blond) for method 1 measurements and $7.13 \%$ (black) and $8.09 \%$ (blond) for method 2 measurements. Because method 1 was better at separating populations known to be distinct based on song type (see above), it was adopted as the standard protocol for analyzing claw data. With respect to the ratios specifying the shape of the genital lip, four males (of four examined) possessing blond setae conformed to the condition seen in $C c 4$ rather than to that of $C c 2$.

Larval Morphology. Cc2 and Cc4 larval head capsule markings (Fig. 7) were dominated by a pair of longitudinal, dorso-lateral brown stripes with baso-lateral expansions extending toward the eyes. This pattern is typical for larvae of Chrysoperla spp. First-instar larvae had the palest and broadest (relative to head width) dorso-lateral stripes and the least developed basolateral expansions. Second-instar larvae were intermediate and third-instar larvae had the darkest and relatively narrowest dorso-lateral stripes and most extensive baso-lateral expansions. All instars varied within and among populations. The remainder of the results focuses on third-instar larvae.

$C c 2$ populations ( $n=1-55$; Fig. 7 ) had a narrow, usually pale (Swiss populations) to moderately broad and darker (French and Italian populations) dorsolateral stripe. The size and prominence of the basolateral expansion showed a parallel trend, being smaller and paler in the Swiss populations. The prominence of the darker spot in the stripe, mesad of the eyes, varied but did not follow a clear geographic pattern. All populations with multiple representatives revealed variation in the width, color intensity and regularity of the margins of the dorso-lateral stripes, in the prominence of the darker spot mesad of the eyes, and in the development of the baso-lateral expansion. Two other variations were noted (Fig. 7). Some individuals from the Traffiume, Italy population had a pair of small spots mesad of the dorso-lateral stripe at the level of the antennal bases, while several specimens from the Vouvray and Zürich populations had the lateral stripe behind the eye visible in dorsal view.

Cc4 populations ( $n=1-68$; Fig. 7 ) showed considerably more variation than $C c 2$ both within and among populations. The dorso-lateral stripes were usually moderately broad to very broad (e.g., Brissago), although in some specimens from Russia (Belgorod) they were atypically narrow. The medial portion or the entire dorso-lateral stripe was generally dark. Variation in the width, tone and margins of the dorsolateral stripe was noted within populations represented by multiple individuals. Except in the atypical Russian specimens just mentioned, the baso-lateral expansion was consistently well developed, but its prominence was obscured by the width of the dorsolateral stripe in some populations (e.g., Berchtesgaden). Most larvae of Cc4 also possessed a darker spot in the stripe mesad of the eyes, an antero-medial spot at the level of the antennal bases, and a pair of frontal spots near the bifurcation of the epicranial suture. However, these markings were absent in the Russian specimens bearing narrow dorso-lateral stripes. Only larvae from the Ukrainian population (Rachiv) commonly had the lateral stripe behind the eyes visible in dorsal view.

Some Cc4 larvae from Finland, Russia, and Switzerland had additional head markings (Fig. 7). The simplest of these more extensively pigmented forms had a larger, triangular antero-medial spot that was usually fused to two pairs of additional triangular spots that lay between the dorso-lateral stripes and the antero-medial spot (e.g., Tammela). Other 'ornate' specimens, taken from the Belgorod, Cavaglio, Bollingen, and Zürich populations, had most of the frons pigmented, uniting all three of the typical spots into a large, triangular pigmented area. These larvae also had the dorso-lateral stripe extremely broad, expanded nearly to the eye, and complexly patterned with lighter and darker tones.

When compared, third-instar larvae of Cc2 and Cc4 could be readily distinguished from each other in all areas where they co-occurred and where larvae of both species were examined. Cc2 larvae lacked the antero-medial and frontal spots that were present in all known sympatric populations of $C c 4$. The only population of $C c 4$ known to include some individuals that lacked the antero-medial and frontal spots (Belgorod, Russia) was situated far to the east of known $C c 2$ localities. However, the two species could not be so easily separated from larvae of other cryptic species in the carnea group. Chrysoperla lucasina, for example, included populations with larval specimens that resembled both Cc2 or Cc4 (see Henry et al. 1996). 


\section{Cc2 'slow-motorboat' = Chrysoperla pallida sp. $\mathrm{n}$.}

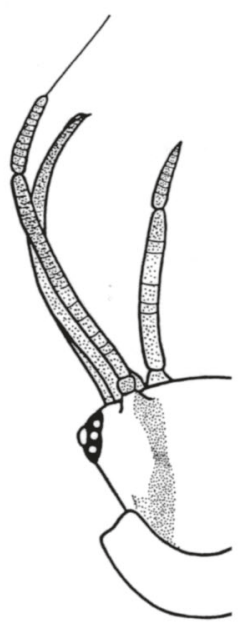

Brissago, Switzerland
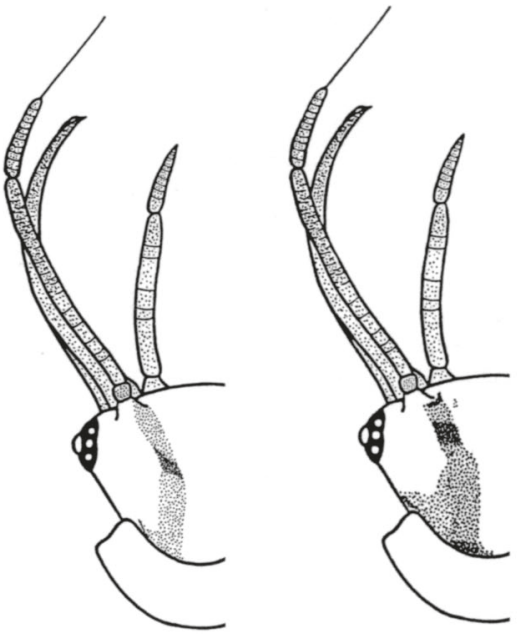

Caslano, Switzerland

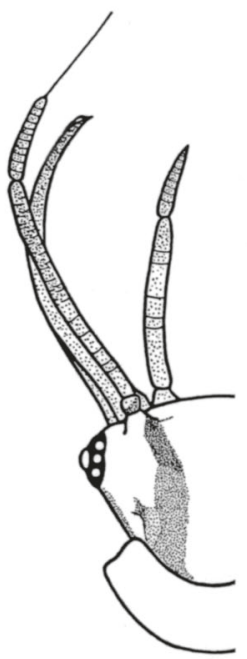

Traffiume, Italy

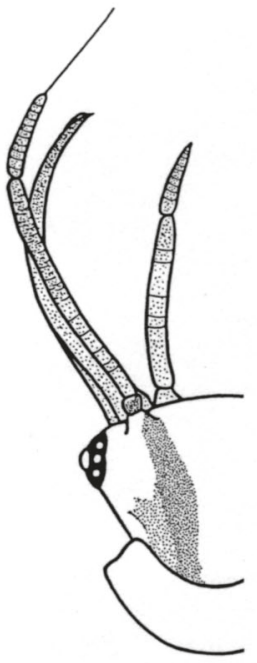

Carcès, France

\section{Cc4 'motorboat' = Chrysoperla carnea (Stephens)}
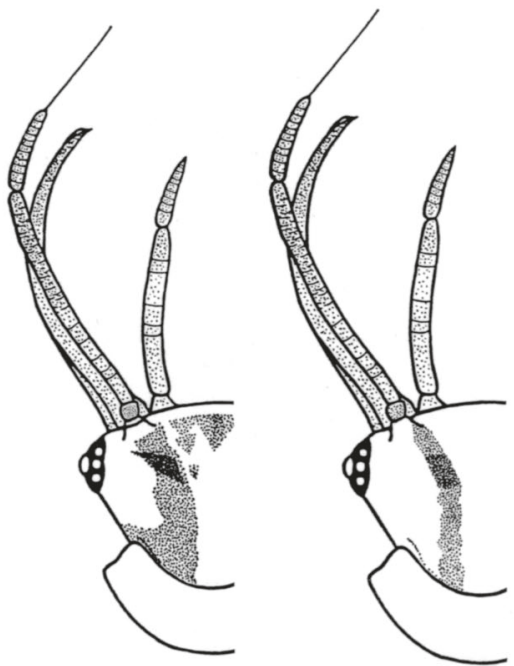

Tammela, Finland
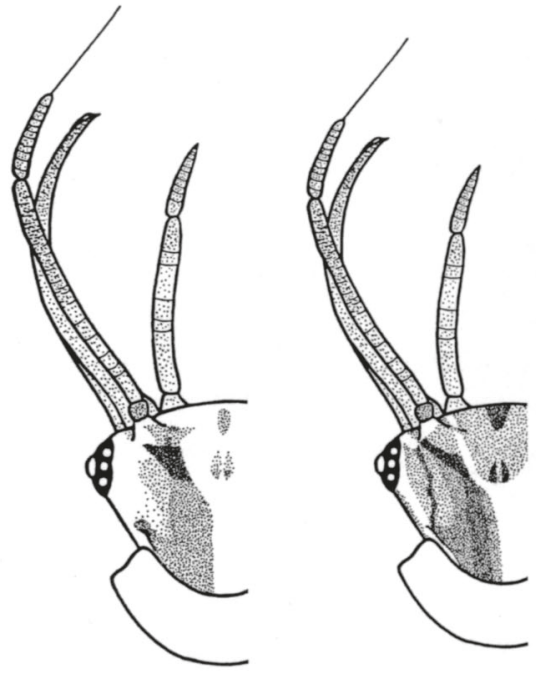

Zürich, Switzerland

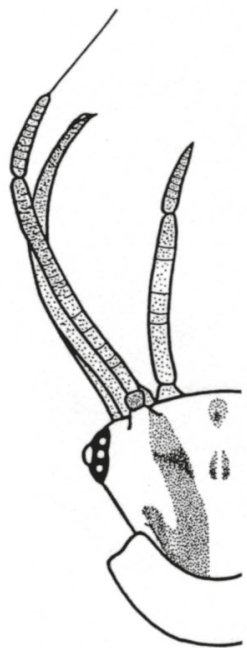

Brissago, Switzerland

Fig. 7. Third-instar larval head capsules of Cc2 (C. pallida) and Cc4 (C. carnea) from selected localities across Europe. Extremes of variation in $C c 4$ are represented by the specimens from Belgorod, Russia ('Cc2-like') and Zürich, Switzerland ('ornate'). The Brissago, Switzerland specimen of Cc4 represents the commonest pattern seen in that species. 


\section{Discussion}

Although the mating songs of $C c 2$ and $C c 4$ resemble each other in fundamental structure and mode of exchange between sexual partners, there is nothing ambiguous about their differences, and it is impossible to mistake the song of one for that of the other (Figs. 1 and 3). In our experience, intermediate songs do not exist. That is a consequence of very low variance in each song feature within and among individuals and among geographic populations of a given song species as quantified by coefficients of variation and analyses of variance (Tables 2 and 3). The songs of $C c 2$ and $C c 4$ are also measurably (and significantly) distinct from those of any of the other seven species of the carnea group used in the discriminant function analysis (Table 4), and, in fact, the discriminant function analysis demonstrated that each of the nine cryptic species possesses a unique song phenotype. Nonetheless, some species pairs are more disparate than others, and overlapping song features are occasionally found in separate song species. However, only allopatric species pairs, and particularly those located on two different continents, exhibit any striking acoustical similarities. This is the expected pattern, if biotic interactions have acted in sympatry to maintain, exaggerate, or reinforce species differences in mating signal systems (Butlin 1987, Howard 1993, Liou and Price 1994, Saetre et al. 1997, Henry et al. 1999a).

Behavioral data support the distinctiveness of songs in $C c 2$ and $C c 4$. Individuals always reject songs of the 'wrong' taxon by never responding to them with songs of their own (Table 6). These results are the very best confirmation of complete premating reproductive isolation between $C c 2$ and $C c 4$ and of their status as separate, valid species. They also mirror results obtained in behavioral tests between other pairs of sibling species in the carnea group (Wells and Henry 1992a, 1992b, 1994; Henry et al. 1999a). Ecological differences are congruent with behavioral ones: $C c 2$ is fundamentally an arboreal species, while $C c 4$ is strongly associated with meadows and croplands, except when overwintering. In addition, morphological differences can be detected between $C c 2$ and $C c 4$ for both adults and larvae, further strengthening the idea that they are distinct species. In all areas of sympatry, adult males of the two species can be distinguished by morphological differences in sternite $8+9$ (Fig. 5), and third-instar larvae of the two species can be told apart by markings on the head capsule (Fig. 7).

Biogeographic and ecophysiological data point to either Cc2 or Cc4 as the 'true' carnea of Stephens, which he described from a British specimen. Of the six European song species of the carnea group, only those two taxa range sufficiently far north (Fig. 2) and undergo the winter diapause color change required to match the "bright rosy-red, or flesh-color" ground color of Stephens' description. Cc4 appears to be much more abundant and widespread than $C c 2$ in the United Kingdom, and its reddish-brown diapause pigmentation is closer to Stephens' description of C. carnea than is the yellowish-brown winter color of $C c 2$. For those reasons, it is tempting to designate $C c 4$ 'motorboat' as the type of Chrysoperla carnea (Stephens) without further deliberation. Yet some of the adult morphological evidence makes acceptance of $C c 4$ as true $c a r$ nea less certain.

The average states of several morphological characters of adults are different in $C c 2$ and $C c 4$ based on examination of 79 song-determined specimens from different localities. In general, the sternal setae on the three terminal segments of the abdomen are blond in $C c 2$ but black in $C c 4$; the maxillary stipes has light marks in $C c 2$ but tends to be broadly marked with a dark stripe in $\mathrm{Cc} 4$; the basal dilation of the claw of the metathoracic leg is broad in $C c 2$ but narrower in $C c 4$ (Fig. 4); and the genital lip of the male abdomen is narrow and small in $C c 2$ but broad and prominent in Cc4 (Fig. 5). These morphological differences have been found to be statistically significant, but overlap or presence in only one sex prevents any single feature from diagnosing one species to the exclusion of the other. Therefore, the temptation to use morphology to diagnose species in the absence of song information should be avoided for now. That said, it is precisely morphology that we must fall back upon to assign a song species to $C$. carnea, because we are certainly never going to get the lectotype to sing again.

The several morphological features distinguishing song-determined $C c 2$ from $C c 4$ were not always correlated in the numerous specimens of the carnea group culled from the British Collection. With both song species demonstrably present in the United Kingdom, we expected that specimens with blond (' $C c 2$ ') versus black ('Cc4') setae would exhibit species-appropriate differences in claw dimensions, but this was not the case: all the specimens examined in both blond and black categories presented claw measurements in the Cc4 range (see Results). The genital lip character in blond-haired specimens also matched the Cc4 condition. Only the specimens from Buckingham Palace Gardens (London) and Silwood Park exhibited the full suite of $C c 2$ character states, including blond setae, lightly marked stipes, relatively broad claw basal dilation, and small, narrow genital lip (Table 7). Based on these results, it seems likely that $C c 4$ is much more common than $C c 2$ in England. Indeed, in view of the absence of $C c 2$ morphotypes from the extensive $\mathrm{BMNH}$ British Collections, it is possible that $\mathrm{Cc} 2$ is a recent introduction to the United Kingdom, arriving with plants imported to gardens in and around London. The results also suggest that blond setae should be used to distinguish specimens of $C c 2$ from $C c 4$ only in conjunction with other features, especially shape of the claw and genital lip.

The specimens in the Stephens Collection are ambiguous with respect to diagnostic morphological characters (Table 7). In the lectotype of C. carnea, the pale setae and lightly marked stipes suggest $C c 2$, but the claw measurements cluster with $C c 4$. One of the females in the type series also has blond setae and a low claw ratio closer to the mean of $C c 2$, and the two 'C. alba' specimens display mixed and intermediate character states. Chrysoperla affinis is clearly $\mathrm{Cc} 4$ in all 
respects as are the remaining five specimens of the type series. The genital lip character cannot lend additional insight, because the lectotypes of both $C$. carnea and C. affinis are females. The lip is Cc4-like in the blond male specimen of ' $C$. alba' and in the other males of the type series. In fact, it is clear from the original descriptions that Stephens never noticed any of the subtle morphological features considered here to distinguish $C c 2$ from $C c 4$. He based C. carnea simply on specimens in winter coloration, whereas C. affinis referred to other specimens in summer coloration. There is, therefore, no conclusive evidence that any of the specimens in Stephens type series should be referred to $C c 2$, whereas the morphological, distributional, and ecophysiological (diapause color) evidence indicate that all the specimens are encompassed by character states shown by $C c 4$. Based on all available evidence, we are designating $\mathrm{Cc4}$ as the song species corresponding to Chrysoperla carnea (Stephens). This decision will also help to maintain stability in the literature: most of the numerous agroenvironmental and biocontrol studies on 'C. carnea' in Europe are referable to $C c 4$, because $C c 2$ does not occur in agricultural biotopes. Chrysoperla affinis (Stephens) remains in synonymy with C. carnea and a new name, Chrysoperla pallida sp. nov., is proposed for $C c 2$, whose phenotype fits that of no other previously described species. A formal description of $C$. pallida is given at the end of this paper.

In the Loire Valley of France, lacewings with the general morphotype of $\mathrm{Cc} 2$ have been called C. carnea (Stephens) for several years, while those closer to the morphotype of Cc4 have been placed in Chrysoperla kolthoffi (Navás) (Leraut 1992, Thierry et al. 1995). Specimens of those two 'species' have been separated using multivariate morphological techniques, applied primarily to claws, and their first-instar larvae were shown to differ in relative levels of "melanisation" (Thierry et al. 1992, 1998). However, these methods suffer from an absence of independent tests of key hypotheses, because the taxonomic units are themselves partially segregated using the very feature under study, e.g., pretarsal claw shape. An additional problem is lack of differences between 'carnea' and 'kolthoffi' in other parts of Europe (Duelli 1996). Finally, C. kolthoffi, originally described from China, is presently a synonym of C. nipponensis (Okamoto) from east Asia and the Philippines and therefore is incorrectly applied to a western European taxon (Brooks 1994). Other song species occur in eastern Asia (Wells and Henry 1998, Henry et al. 1999a), but $C c 2$ and $C c 4$ have yet to be found there. We recommend abandoning informal usage of the names 'carnea' and 'kolthoff' and instead applying the name C. carnea only to song-determined members of $C c 4$, or, as our ability to use morphology to diagnose song species improves, to unambiguous Cc4 morphotypes. What has been called 'kolthoff' in central Europe by Leraut (1992) and Thierry et al. (1995) becomes C. carnea (Stephens) (Fig. 2).

At present, the phylogenetic positions of C. pallida $(C c 2)$ and $C$. carnea (Cc4) within the carnea group cannot be determined beyond the certainty that both are more closely related to other Eurasian song species than to North American ones (see Fig. 3 in Henry et al. 1999a). Although there is resolution of species relationships within the North American clade based on rapidly evolving mitochondrial DNA sequences, the 10 Eurasian species remain clumped together in the phylogenetic analysis as a large polytomy.

The carnea group of Chrysoperla is one of the largest complexes of sibling, cryptic species yet described in animals, rivaling or exceeding in size well-known species flocks of Anopheles mosquitoes (many complexes, Paterson 1962, Mayr 1963, Lambert 1983, Subbarao et al. 1994, Wilkerson et al. 1995, Reinert et al. 1997), Drosophila yeast flies (several species groups, Spassky et al. 1971, Ayala and Tracey 1974, Chang and Miller 1978), Thraxon bee flies (Yeates and Lambkin 1998), Photuris fireflies (Barber 1951), Gryllus field crickets (Harrison 1979), Oecanthus tree crickets (Walker 1963, 1964), Rana pipiens frogs (Hillis 1988), and Plethodon salamanders (Highton 1995). Unlike the species in the carnea group, however, species within those other complexes of sibling species nearly always show clear interspecific differences in their allozymes and DNA sequences (e.g., Ayala et al. 1974, Funk et al. 1988, Hillis 1988, Knowlton 1993, Wilkerson et al. 1995). In the carnea group, poor phylogenetic resolution within such a large number of cryptic species despite the use of relatively 'fast' genes probably reflects extreme recency of species-level divergence, and indicates that new species have proliferated rapidly. Results from an earlier study of allozymes support that interpretation. Among three of the North American song species, Nei's genetic distance $(D)$ measured 0.03-0.06 (Wells 1994), which is in the range typically seen among local populations and much lower than has been found in other groups of insect sibling species (Brussard et al. 1985). Very rapid speciation accompanied by minimal morphological and genetic changes is probably a consequence of the unusual premating behavior of carnea-group lacewings in which both sexes sing equally and must match their songs before copulating (self recognition, e.g., Ryan and Getz 2000). Such a system circumvents the necessity for one sex to track evolutionary changes in the mating behavior of the other sex in a time-consuming coevolutionary process, resulting in more rapid stabilization of new mate recognition patterns during cladogenesis.

\section{Chrysoperla pallida sp. nov.}

(Figs. 1 and 3, 5, 7-'Cc2')

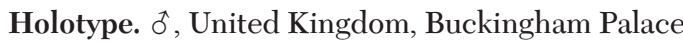
Gardens, London, 21-II-2000, S. J. Brooks and C. W. Plant. Deposited in British Museum of Natural History, London, UK. PARATYPES. 10 \%, 6 $q$, same data. Depositories: 1 , British Museum of Natural History, London, UK; 1 o, 1 q, CT State Museum of Natural History, Storrs, CT, USA; 2 우, William F. Barr Museum, Moscow, ID, USA; 2 $q$, Swiss Federal Institute for Forest, Snow and Landscape Research, Bir- 
mensdorf, Switzerland; five first-, second-, and thirdinstar larvae, British Museum of Natural History, London, UK; five first-, second-, and third-instar larvae, William F. Barr Museum, Moscow, ID, USA.

Etymology. Named for its relatively pale pigmentation and predominantly blond setae on the wings and body.

Adult. Head marked with narrow brown stripe on gena and lateral clypeus. Maxillary palps unmarked or marked with dorsal black stripe. Antennae shorter than fore wing. Pronotum marked with median yellow stripe; lateral setae long, pale; dorsal setae shorter, dark or mixed with pale setae. Claw basal dilation ratio 1.67-2.14. Fore wing length $11.5-14 \mathrm{~mm}$; length/breadth ratio 2.9-3.3; crossveins in basal half of wing brown or green with brown spot at ends; gradates green. Abdomen with blond setae on apical sternites; lip of sternite $8+9$ in male short, narrow, with short blond setae.

Courtship Song $\left(\mathbf{2 5}^{\circ} \mathrm{C}\right)$. Long (3.4-90 s), consisting of numerous short (approx. $200 \mathrm{~ms}$ ) volleys of abdominal vibration; volley period $\approx 300 \mathrm{~ms}$; carrier frequency modulated between 50 and $77 \mathrm{~Hz}$, highest shortly after song begins; abdomen sharply strikes the substrate during latter two-thirds of each song.

Larva. Dorsum of head with a pair of relatively narrow longitudinal, dorso-lateral brown stripes with baso-lateral expansions extending toward the eyes; stripes and lateral expansions most sharply delineated in third-instar (mature) individuals. In a small proportion of individuals, a pair of small spots is present mesad of the dorso-lateral stripe at the level of the antennal bases.

Diagnosis. The adult of C. pallida is very similar to C. carnea and is best separated from that species by song analysis. Both species produce long, multi-volley songs, but the volleys of C. pallida are significantly longer and spaced further apart than those of C. car$n e a$, and the carrier frequency declines during its song rather than remaining constant or rising. The only morphological character that will reliably distinguish adults of the species from each other is the shape of the genital lip on sternite $8+9$ in males. In C. pallida the lip is short and narrow and bears very short pale setae. In C. carnea the lip is broader and more protuberant and bears several long, coarse dark setae. Chrysoperla lucasina, with which C. pallida may also be confused, has a diagnostic brown stripe on the pleural membrane of the second abdominal segment, and produces a mating song distinguished by much longer $(1 \mathrm{~s})$ volleys. $C c 3$ also resembles $C$. pallida very closely but differs in mating song; those two song species cannot as yet be separated using morphology.

Most larval specimens of C. pallida can be distinguished from C. carnea (Stephens) by the absence of any head markings (spots) mesad of the dorso-lateral stripes. Although extra markings are also lacking in a few specimens of C. carnea from Russia, C. pallida does not occur that far north and east, precluding confusion of one species with the other there. Unfortunately, the color patterns characteristic of larvae of C. pallida overlap significantly with some specimens of $C$. $l u$ casina and C. mediterranea, both of which can be found in sympatry with it.
Distribution. United Kingdom, Spain, France, Switzerland, Italy, Greece, Germany, Hungary.

\section{Acknowledgments}

This study was supported in part by NSF Award DEB9220579 to Charles S. Henry and by the Research Foundation of University of Connecticut. We thank Monsieur Roger Cloupeau (10 Avenue Brullé, 37210 Vouvray, France), Dominique Thierry (Institut de Recherche Fondamentale et Appliquée - Université Catholique de l'Ouest, Department des Sciences de la Vie et de la Terre, 49000 Angers, France), Andrew Whittington (National Museums of Scotland, Edinburgh, Scotland EH1 1JF), and Colin W. Plant (14 West Road, Bishops Stortford, Hertfordshire, England) for collecting and sending the living lacewings used in the song playback experiments. Mark Lane allowed us access to Buckingham Palace Gardens. Bart Donato (Department of Biology, Imperial College, Silwood Park, Ascot, Berkshire, England) kindly shared with us important lacewing specimens obtained from his aphid pheromone traps at the Silwood Park field station. David Wagner (University of Connecticut) skillfully mounted all dried specimens used in this study. Additional thanks go to the first author's valued colleague at University of Connecticut, Marta Lucía Martínez Wells, for her help in designing and implementing the behavioral choice tests, and to Peter Barnard (BMNH) for enlightening discussions regarding the status of specimens in the Stephens collection. Several anonymous reviewers improved the manuscript with their constructive comments.

\section{References Cited}

Ayala, F. J., M. L. Tracey, D. Hedgecock, and R. Richmond. 1974. Genetic differentiation during the speciation process in Drosophila. Evolution 28: 576-592.

Ayala, G. J., and M. L. Tracey. 1974. Genetic differentiation within and between species of the Drosophila willistoni group. Proc. Natl. Acad. Sci. U.S.A. 71: 999-1003.

Bailey, W. J. 1991. Acoustic Behavior of Insects: An Evolutionary Perspective. Chapman \& Hall, New York.

Barber, H. S. 1951. North American fireflies of the genus Photuris. Smithsonian Miscel. Coll. 117: 1-58.

Baric, S., and C. Sturmbauer. 1999. Ecological parallelism and cryptic species in the genus Ophiothrix derived from mitochondrial DNA sequences. Mol. Phylogenet. Evol. 11: $157-162$

Beeman, K. 1996. Signal/RTS User's Guide. Engineering Design, Belmont, Massachusetts.

Bernardi, G., and U. Goswami. 1997. Molecular evidence for cryptic species among the Antarctic fish Trematomus bernacchii and Trematomus hansoni. Antarc. Sci. 9: 381-385.

Bram, R. A., and W. E. Bickley. 1963. The green lacewings of the genus Chrysopa in Maryland (Neuroptera: Chrysopidae). University of Maryland Agricultural Experiment Station, Bulletin A-124: 1-18.

Brooks, S. J. 1994. A taxonomic review of the common green lacewing genus Chrysoperla (Neuroptera: Chrysopidae). Bull. Br. Mus. Nat. Hist. (Entomol.) 63: 137-210.

Brussard, P. F., P. R. Ehrlich, D. D. Murphy, B. A. Wilcox, and J. Wright. 1985. Genetic distances and the taxonomy of checkerspot butterflies (Nymphalidae: Nymphalinae). J. Kansas Entomol. Soc. 58: 403-412.

Butlin, R. K. 1987. Species, speciation and reinforcement. Am. Nat. 130: 461-464. 
Chang, H. C., and D. D. Miller. 1978. Courtship and mating sounds in species of the Drosophila affinis subgroup. Evolution 32: 540-550.

Duelli, P. 1986. Flight activity patterns in lacewings (Planipennia: Chrysopidae), pp. 165-170. In J. Gepp, H. H. Aspöck and H. Hölzel [eds.], Recent Res. in Neuropterology. Proceedings of the 2nd International Symposium in Neuropterology. Thalerhof, Graz, Austria.

Duelli, P. 1988. Aphidophaga and the concepts of island biogeography in agricultural areas, pp. 89-93. In E. Niemczyk and A.F.G. Dixon [eds.], Ecology and Effectiveness of Aphidophaga. SPB Academic Publishing, The Hague.

Duelli, P. 1996. The working group "carnea-complex:" Report on activities, results and cooperative projects, pp. 307-311. In M. Canard, H. Aspöck and M. W. Mansell [eds.], Pure and Applied Res. in Neuropterology. Proceedings of the Fifth International Symposium on Neuropterology. Cairo, Egypt, 1994. Sacco, Toulouse, France.

Duelli, P. 2001. Lacewings in field crops, pp. 158-171. In P. K. McEwen, T. R. New and A. E. Whittington [eds.], Lacewings in the Crop Environment. Cambridge University Press, Cambridge, England, UK.

Ewing, A. W. 1989. Arthropod Bioacoustics. Neurobiology and Behavior. Cornell University Press, Ithaca, New York.

Funk, D. H., B. W. Sweeney, and R. L. Vannote. 1988. Electrophoretic study of eastern North American Eurylophella (Ephemeroptera: Ephemerellidae) with the discovery of morphologically cryptic species. Ann. Entomol. Soc. Am. 81: 174-186.

Gerhardt, H. C. 1994. The evolution of vocalization in frogs and toads. Annu. Rev. Ecol. Syst. 25: 293-324.

Green, D. M., H. Kaiser, T. F. Sharbel, J. Kearsley, and K. R. McAllister. 1997. Cryptic species of spotted frogs, Rana pretiosa complex, in western North America. Copeia: 1-8.

Hagen, K. S., and R. L. Tassan. 1970. The influence of food Wheast and related Saccharomyces fragilis yeast products on the fecundity of Chrysopa carnea (Neuroptera, Chrysopidae). Can. Entomol. 102: 806-811.

Harrison, R. G. 1979. Speciation in North American field crickets: evidence from electrophoretic comparisons. Evolution 33: 1009-1023.

Henry, C. S. 1979. Acoustical communication during courtship and mating in the green lacewing Chrysopa carnea (Neuroptera: Chrysopidae). Ann. Entomol. Soc. Am. 72: $68-79$.

Henry, C. S. 1980a. The importance of low-frequency, substrate-borne sounds in lacewing communication (Neuroptera: Chrysopidae). Ann. Entomol. Soc. Am. 73: 617-621.

Henry, C. S. 1980b. The courtship call of Chrysopa downesi Banks [sic] (Neuroptera: Chrysopidae): its evolutionary significance. Psyche 86: 291-297.

Henry, C. S. 1985. Sibling species, call differences, and speciation in green lacewings (Neuroptera: Chrysopidae: Chrysoperla). Evolution 39: 965-984.

Henry, C. S. 1991. The status of the P2 song morph, a North American green lacewing of the Chrysoperla carnea species-group (Neuroptera: Chrysopidae). Can. J. Zool. 69: 1805-1813.

Henry, C. S. 1993. Chrysoperla mohave (Banks) (Neuroptera: Chrysopidae): two familiar species in an unexpected disguise. Psyche 99: 291-308.

Henry, C. S., and C. Busher. 1988. Patterns of mating and fecundity in several common green lacewings (Neuroptera: Chrysopidae) of eastern North America. Psyche 94: 219-244.

Henry, C. S., and M. M. Wells. 1990. Geographical variation in the song of Chrysoperla plorabunda in North America
(Neuroptera: Chrysopidae). Ann. Entomol. Soc. Am. 83: 317-325.

Henry, C. S., M. M. Wells, and R. J. Pupedis. 1993. Hidden taxonomic diversity within Chrysoperla plorabunda (Neuroptera: Chrysopidae): two new species based on courtship songs. Ann. Entomol. Soc. Am. 86: 1-13.

Henry, C. S., M.L.M. Wells, and C. M. Simon. 1999a. Convergent evolution of courtship songs among cryptic species of the carnea-group of green lacewings (Neuroptera: Chrysopidae: Chrysoperla). Evolution 53: 1165-1179.

Henry, C. S., S. J. Brooks, J. B. Johnson, and P. Duelli. 1996. Chrysoperla lucasina (Lacroix): a distinct species of green lacewing, confirmed by acoustical analysis (Neuroptera: Chrysopidae). Syst. Entomol. 21: 205-218.

Henry, C. S., S. J. Brooks, P. Duelli, and J. B. Johnson. 1999b. Revised concept of Chrysoperla mediterranea (Hölzel), a green lacewing associated with conifers: Courtship songs across 2800 kilometers of Europe (Neuroptera: Chrysopidae). Syst. Entomol. 24: 335-350.

Henry, C. S., S. J. Brooks, D. Thierry, P. Duelli, and J. B. Johnson. 2001. The common green lacewing (Chrysoperla carnea s. lat.) and the sibling species problem, pp. 29-42. In P. K. McEwen, T. R. New and A. E. Whittington [eds.], Lacewings in the Crop Environment. Cambridge University Press, Cambridge, England, UK.

Highton, R. 1995. Speciation in eastern North American salamanders of the genus Plethodon. Annu. Rev. Ecol. Syst. 26: $579-600$.

Hillis, D. M. 1988. Systematics of the Rana pipiens complex: Puzzle and paradigm. Annu. Rev. Ecol. Syst. 19: 39-63.

Hölzel, H. 1972. Anisochrysa (Chrysoperla) mediterranea n. sp. eine neue europäische Chrysopiden-Spezies (Planipennia, Chrysopidae). Nachricht. Bayerisch. Entomol. 21: 81-83.

Howard, D. J. 1993. Reinforcement: Origin, dynamics, and fate of an evolutionary hypothesis, pp. 46-69. In R. G. Harrison [ed.], Hybrid Zones and the Evolutionary Process. Oxford University Press, New York.

Jackson, J. K., and V. H. Resh. 1998. Morphologically cryptic species confound ecological studies of the caddisfly genus Gumaga (Trichoptera: Sericostomatidae) in Northern California. Aquat. Insects 20: 69-84.

Jones, G. 1997. Acoustic signals and speciation: The roles of natural and sexual selection in the evolution of cryptic species. Advances in the Study of Behav. 26: 317-354.

Kimmins, D. E. 1964. The British species of the genus Athripsodes, with comments on the species described by Stephens (Trichoptera, Leptoceridae). Entomologist's Gazette 15: 153-180.

Knowlton, N. 1986. Cryptic and sibling species among the decapod Crustacea. J. Crustacean Biol. 6: 356-363.

Knowlton, N. 1993. Sibling species in the sea. Annu. Rev. Ecol. Syst. 24: 189-216.

Kroodsma, D. E. 1989. Suggested experimental designs for song playbacks. Anim. Behav. 37: 600-609.

Lambert, D. M. 1983. A population genetical study of the African mosquito Anopheles marshallii (Theobald). Evolution 37: 484-495.

Leraut, P. 1991. Les Chrysoperla de la faune de France (Neuroptera Chrysopidae). Entomol. Gallica 2: 75-81.

Leraut, P. 1992. Névroptères des Alpes centrales françaises (Neuroptera). Entomol. Gallica 3: 59-65.

Liou, L. W., and T. D. Price. 1994. Speciation by reinforcement of premating isolation. Evolution 48: 1451-1459.

Mayr, E. 1963. Animal Species and Evolution. Belknap Press of Harvard University Press, Cambridge, MA.

Michelsen, A., F. Fink, M. Gogala, and D. Traue. 1982. Plants as transmission channels for insect vibrational songs. Behav. Ecol. Sociobiol. 11: 269-281. 
Morris, G. K. 1980. Calling display and mating behavior of Copiphora rhinoceros Pictet (Orthoptera: Tettigoniidae). Anim. Behav. 28: 42-51.

Paterson, H. E. 1962. On the status of the East African saltwater-breeding variant of Anopheles gambiae Giles. Nature (Lond.) 195: 469-470.

Paterson, H.E.H. 1991. The recognition of cryptic species among economically important insects, pp. 1-10. In M. P. Zalucki [ed.], Heliothis: Res. Methods and Prospects. Springer, New York.

Reinert, J. F., P. E. Kaiser, and J. A. Seawright. 1997. Analysis of the Anopheles (Anopheles) quadrimaculatus complex of sibling species (Diptera: Culicidae) using morphological, cytological, molecular, genetic, biochemical, and ecological techniques in an integrated approach. J. of the Am. Mosquito Control Association 13: 1-102.

Ryan, M. J., and W. Getz. 2000. Signal decoding and receiver evolution - An analysis using an artificial neural network. Brain Behav. Evol. 56: 45-62.

Saetre, G. P., T. Moum, S. Bures, M. Kral, M. Adamjan, and J. Moreno. 1997. A sexually selected character displacement in flycatchers reinforces premating isolation. Nature (Lond.) 387: 589-592.

Scheffé, H. 1953. A method for judging all possible contrasts in the analysis of variance. Biometrika 40: 87-104.

Séméria, Y. 1977. Discussion de la validité taxonomique du sous-genre Chrysoperla Steinmann (Planipennia, Chrysopidae). Nouv. Rev. Entomol. 7: 235-238.

Smith, G. 1995. Spike2 for Windows, User's Manual. Cambridge Electronic Design Limited, Cambridge, England.

Snedecor, G. W., and W. G. Cochran. 1980. Statistical Methods. Iowa State University Press, Ames, Iowa.

Spassky, B., R. C. Richmond, S. Perex-Salas, O. Pavlovsky, C. A. Mourao, A. S. Hunter, H. Hoenigsberg, T. Dobzhansky, and F. J. Ayala. 1971. Geography of the sibling species related to Drosophila willistoni and of the semispecies of the Drosophila paulistorum complex. Evolution 25: $129-143$

Statistica. 1999. Statistica for Windows, version 5.5A. Statistica, Statsoft, Inc., Tulsa, O.K.

Stephens, J. F. 1835. Illustrations of British Entomology; or, A Synopsis of Indigenous Insects: Containing their Generic and Specific Distinctions, with an Account of their Metamorphoses, Times of Appearance, Localities, Food, Economy. Mandibulata vol 6. Balwin \& Cradock, London, UK.

Subbarao, S. K., N. Nanda, K. Vasantha, V. K. Dua, M. S. Malhotra, R. S. Yadav, and V. P. Sharma. 1994. Cytogenetic evidence for three sibling species in Anopheles fluviatilis (Diptera, Culicidae). Ann. Entomol. Soc. Am. 87: $116-121$.

Sweeney, B. W., and D. H. Funk. 1991. Population genetics of the burrowing mayfly Dolania americana: geographic variation and the presence of a cryptic species. Aquat. Insects 13: 17-27.

Tauber, C. A., and M. J. Tauber. 1986. Ecophysiological responses in life-history evolution: evidence for their importance in a geographically widespread insect species complex. Can. J. Zool. 64: 875-884.

Tauber, M. J., C. A. Tauber, K. M. Daane, and K. S. Hagen. 2000. Commercialization of predators: Recent lessons from green lacewings (Neuroptera: Chrysopidae: Chrysoperla). Am. Entomol. 46: 26-38.

Templeton, A. R. 1989. The meaning of species and speciation: a genetic perspective, pp. 3-27. In D. Otte and J. A. Endler [eds.], Speciation and Its Consequences. Sinauer, Sunderland, MA.
Thierry, D., R. Cloupeau, and M. Jarry. 1992. La Chrysope commune Chrysoperla carnea (Stephens) sensu lato dans le centre de la France: mise en évidence d'un complexe d'espèces (Insecta: Neuroptera: Chrysopidae), pp. 379392. In M. Canard, H. Aspöck and M. W. Mansell [eds.], Current Res. in Neuropterology. Proceedings of the Fourth International Symposium on Neuropterology, Bagnères-deLuchon, France, 1991. Sacco, Toulouse, France.

Thierry, D., R. Cloupeau, and M. Jarry. 1995. Variation in the overwintering ecophysiological traits in the common green lacewing West-Palaearctic complex (Neuroptera: Chrysopidae). Acta Oecol. 15: 593-606.

Thierry, D., R. Cloupeau, M. Jarry, and M. Canard. 1998. Discrimination of the West-Palaearctic Chrysoperla Steinmann species of the carnea Stephens group by means of claw morphology (Neuroptera, Chrysopidae). Acta Zool. Fenn. 209: 255-262.

Tjeder, B. 1960. Neuroptera from Newfoundland, Miquelon, and Labrador. Opusc. Entomol. 25: 146-149.

Vrijenhoek, R. C., S. J. Schutz, R. G. Gustafson, and R. A. Lutz. 1994. Cryptic species of deep-sea clams (Mollusca: Bivalvia: Vesicomyidae) from hydrothermal vent and cold-water seep environments. Deep-Sea Res. Part I: Oceanography Res. Papers 41: 1171-1189.

Walker, T. J. 1963. The taxonomy and calling songs of United States tree crickets (Orthoptera: Gryllidae: Oecanthinae). 2. The nigricornis group of the genus Oecanthus. Ann. Entomol. Soc. Am. 56: 772-789.

Walker, T. J. 1964. Cryptic species among sound-producing ensiferan Orthoptera (Gryllidae and Tettigoniidae). Quart. Rev. Biol. 39: 345-355.

Wells, K. D. 1977. The social behavior of anuran amphibians. Anim. Behav. 25: 666-693.

Wells, M. M. 1994. Small genetic distances among populations of green lacewings of the genus Chrysoperla (Neuroptera: Chrysopidae). Ann. Entomol. Soc. Am. 87: 737-744.

Wells, M. M., and C. S. Henry. 1992a. The role of courtship songs in reproductive isolation among populations of green lacewings of the genus Chrysoperla (Neuroptera: Chrysopidae). Evolution 46: 31-42.

Wells, M. M., and C. S. Henry. 1992b. Behavioral responses of green lacewings (Neuroptera: Chrysopidae) to synthetic mating songs. Anim. Behav. 44: 641-652.

Wells, M. M., and C. S. Henry. 1994. Behavioral responses of hybrid lacewings (Neuroptera: Chrysopidae) to courtship songs. J. Insect Behav. 7: 649-662.

Wells, M. M., and C. S. Henry. 1998. Songs, reproductive isolation and speciation in cryptic species of insects: a case study using green lacewings, pp. 217-233. In D. Howard and S. Berlocher [eds.], Endless Forms: Species and Speciation. Oxford University Press, New York.

Wilcox, T. P., L. Hugg, J. A. Zeh, and D. W. Zeh. 1997. Mitochondrial DNA sequencing reveals extreme genetic differentiation in a cryptic species complex of neotropical pseudoscorpions. Mol. Phylogenet. Evol. 7: 208-216.

Wilkerson, R. C., T. J. Parsons, T. A. Klein, T. V. Gaffigan, E. Bergo, and J. Consolim. 1995. Diagnosis by random amplified polymorphic DNA polymerase chain reaction of four cryptic species related to Anopheles (Nyssorhynchus) albitarsis (Diptera: Culicidae) from Paraguay, Argentina, and Brazil. J. Med. Entomol. 32: 697-704.

Yeates, D. K., and C. L. Lambkin. 1998. Cryptic species diversity and character congruence: review of the tribe Anthracini (Diptera: Bombyliidae) in Australia. Invertebrate Taxonomy 12: 977-1078.

Received for publication 1 June 2001; accepted 2 November 2001 